Check for updates

Cite this: Mater. Adv., 2020, 1,2646

Received 19th August 2020, Accepted 3rd October 2020

DOI: $10.1039 / \mathrm{d} 0 \mathrm{ma} 00625 \mathrm{~d}$

rsc.li/materials-advances

\section{Macrocycles-assisted polymeric self-assemblies fabricated by host-guest complexation and their applications}

\author{
Krishnasamy Velmurugan, ${ }^{a}$ Makesh Mohan, ${ }^{b}$ Bin Li, ${ }^{a}$ Kaiya Wang, ${ }^{a}$ Minzan Zuo (D) ${ }^{a}$ \\ and Xiao-Yu Hu iD *a
}

\begin{abstract}
Macrocycles exhibit unique features with prospective applications due to their inherent structural features combined with rigidity and functionality. Developing macrocycles-assisted polymeric selfassemblies (MPs) is one of the promising ways to convert macrocyclic polymers into functional materials with responsiveness, endowing them with realistic features such as self-healing, good processability, and recyclability. The present review focuses on the rational design of MPs, over the past decade, with realistic potential applications. The constructions of MPs mainly focuses on the following facets: (i) those assembled from macrocyclic side-chain polymeric hosts interacting with small molecular/polymeric organic and inorganic guests, and (ii) those assembled from macrocyclic monomers interacting with side-chain polymeric guests. These resultant MPs include the dynamic cross-linking of different copolymeric hosts and/or guests, which further leads to the formation of supramolecular self-assembled nanomaterials with unique functionalities. We also discuss the fabrication of stimuli-responsive MPs that are influenced by various external stimuli, and the resultant supramolecular host-guest complexationmediated reversible self-assemblies are also highlighted. Furthermore, a wide range of applications of MPs, including self-healing materials, adhesives, adsorbents, drug delivery, and smart windows, and their modes of assemblies are elaborately presented. As far as we know, this is the first review particularly focusing on the side-chain polymeric host-guest interactions and their self-assemblies for diverse applications, whereas linear polymers and post-polymerizations are not included. This review summarizes the fundamental design concepts in the fabrication of polymeric backbone-assisted MPs, which provides new directions for future research in the field of supramolecular chemistry and materials chemistry.
\end{abstract}

${ }^{a}$ College of Materials Science and Technology, Nanjing University of Aeronautics and Astronautics, Nanjing 211106, China. E-mail: huxy@nuaa.edu.cn

${ }^{b}$ Department of Physics, National Institute of Technology Karnataka (NITK) Surathkal, India

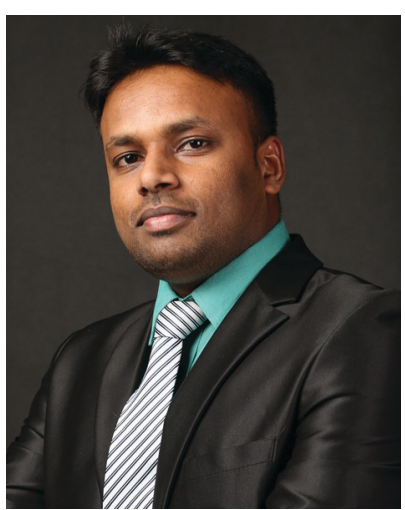

Krishnasamy Velmurugan
Krishnasamy Velmurugan received his $P h D$ in Chemistry from Karunya University, Coimbatore, India. He then conducted postdoctoral research at Xi'an Jiaotong University, P. R. China in 2017. Currently, he is a postdoctoral researcher at Nanjing University of Aeronautics and Astronautics (NUAA), P. R. China, and his research interests are focused on supramolecular chiral self-assemblies and functional materials.

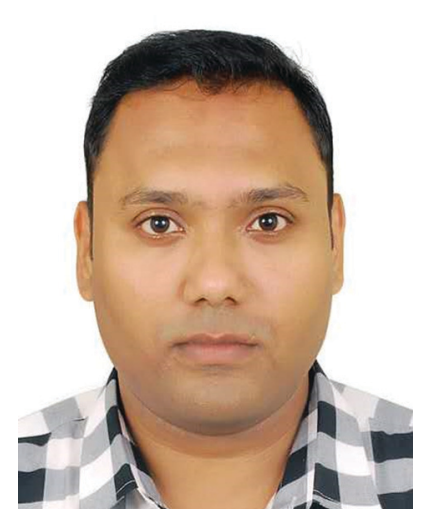

Makesh Mohan
Makesh Mohan received his Master's degree in electronics from VIT University, Vellore, Tamil Nadu in 2012. He recently submitted his doctoral thesis in Physics at the National Institute of Technology Karnataka (NITK) Surathkal, Karnataka, India. His research interests include the design and synthesis of new organic materials for light-emitting applications, and also has interest in quantum chemical computations. 


\section{Introduction}

The progression of new macrocycles-assisted polymeric selfassemblies (MPs) has been playing a key role in our lives and science. Motivated by the exciting functionalities offered by MPs, researchers have strived to develop novel polymeric selfassembled nanomaterials with desired structural features and properties. $^{1,2} \mathrm{~J}$.-M. Lehn first designated the concepts of supramolecular polymers-the productive combination between supramolecular chemistry and polymers. ${ }^{3,4}$ Supramolecular polymers possess arrays of polymeric repeating units that are linked by dynamic non-covalent interactions. ${ }^{5-11}$ This universal methodology permits the fabrication of supramolecular selfassembled nanomaterials. The inherent dynamic properties of MPs are highly advantageous; they offer easy structure adaptation by fine-tuning the assemblies of the constituent polymeric units. MPs are comprised of elegant functional moieties that are involved in cross-linking via host-guest interactions, charge transfer interactions, hydrophobic effects, van der Waals forces, electrostatic interactions, hydrogen bonds, and $\pi-\pi$ stacking.
Specifically, MPs are constructed from the noncovalent crosslinking of organic/inorganic guests with the existing polymeric hosts, thus endowing them with structural flexibility, functional diversity, and ease of modification. ${ }^{12}$ The resultant MPs built from various polymeric backbones with well-designed structural configurations retain amphiphilic subunits that can further selfassemble into nanoaggregates in either water or suitable organic media. ${ }^{13}$ Nanoaggregates so formed are heavily influenced by coordinating or resisting forces arising at the interface between MPs and the surrounding environment. ${ }^{14}$ However, MPs containing functional and tunable polymeric subunits enhance the covalent/noncovalent amphiphilic interactions, which in turn strengthen the stimuli-responsiveness of the systems. ${ }^{15}$ These stimuli-responsive MPs have been utilized for the development of functional materials, which show great potential in sensing, catalysis, hydrogels, and drug (gene) delivery applications. ${ }^{16-18}$

The macrocycle-assisted host-guest strategy is unique, owing to its self-complementary interactions and directional properties. The host-guest interactions have played a crucial

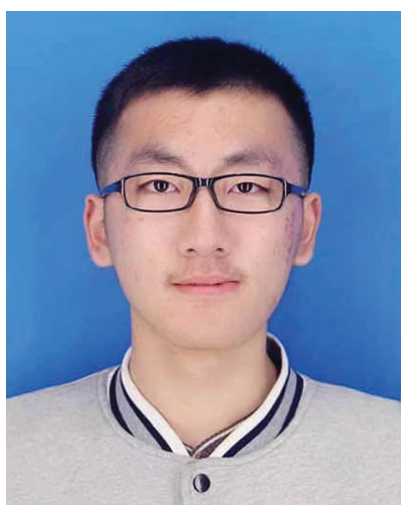

Bin Li obtained his Bachelor's degree at Nanjing University of Aeronautics and Astronautics. $\mathrm{He}$ is currently pursuing his Master's degree at the same college under the guidance of Prof. Xiao-Yu Hu in the field of Supramolecular Chemistry.

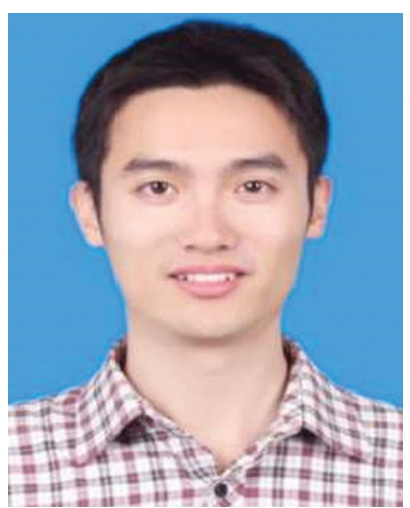

Minzan Zuo
Minzan Zuo received his $P h D$ in 2019 under the supervision of Prof. Leyong Wang and Prof. Xiao$\mathrm{Yu} \mathrm{Hu}$ from Nanjing University. Since 2020, he has joined Prof. Xiao-Yu Hu's group for postdoctoral research at Nanjing University of Aeronautics and Astronautics. His current research interests are focused on supramolecular polymers and functional materials.

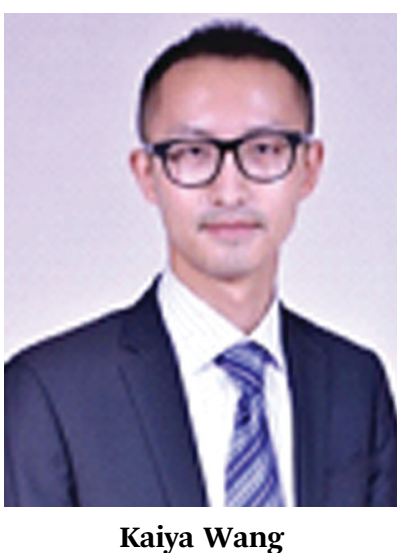

Kaiya Wang received his $P h D$ in Chemistry from Tulane University in 2017, under the supervision of Prof. Bruce C. Gibb. Currently, he is a postdoctoral researcher at Nanjing University of Aeronautics and Astronautics working with Prof. Xiao-Yu Hu. His research interests focus on reactions and protections by supramolecular compartments, and functional supramolecular materials.

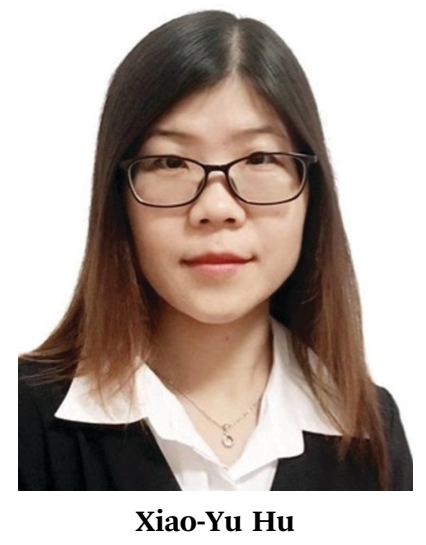
and Astronautics. Her current research interests are focused on supramolecular self-assembly and functional supramolecular materials.
Xiao-Yu Hu received her $\mathrm{PhD}$ in Pharmaceutical Chemistry from Chengdu Institute of Biology (CAS) in 2011. After her postdoctoral research with Prof. Leyong Wang, she joined Nanjing University as an Associate Research Professor in 2013. From 2016 to 2018, she joined University of DuisburgEssen as a senior AvH Fellow with Prof. Carsten Schmuck. Since 2018, she has been appointed as the Professor of Organic Chemistry at Nanjing University of Aeronautics 


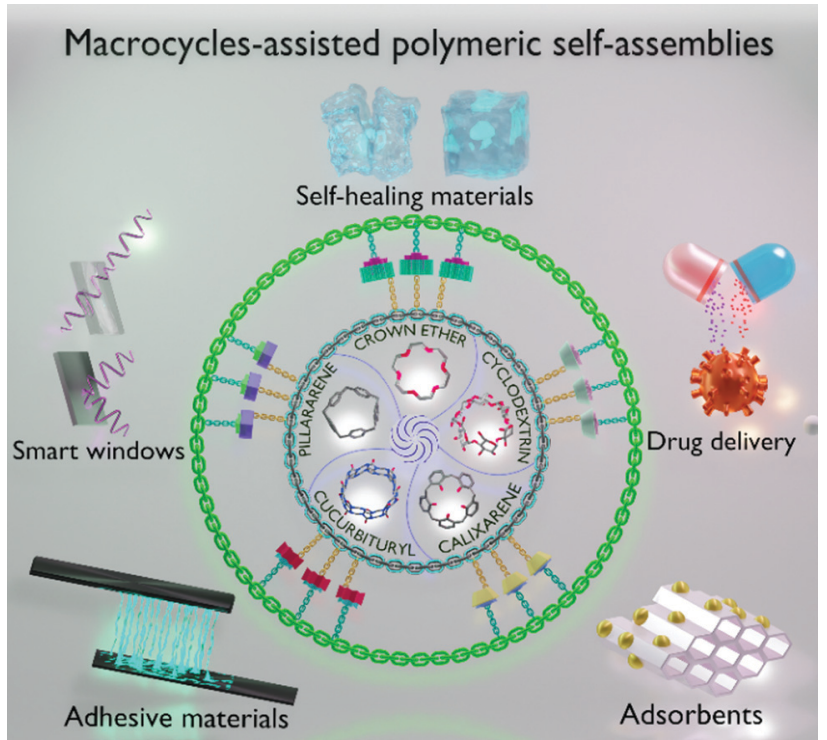

Fig. 1 Graphical representation of the fabrication of different macrocyclesassisted polymeric self-assemblies based on host-guest complexation and their potential applications.

role not only in supramolecular chemistry but also in the field of polymer and materials chemistry. Crown ethers (CEs), cyclodextrins (CDs), cucurbiturils (CBs), calixarenes (CAs), and pillararenes (PAs), are some of the widely known macrocycles used for the construction of supramolecular self-assembled nanoarchitectures via host-guest interactions (Fig. 1). ${ }^{19-22}$ The geometric dimensions of their core cavities non-covalently interact with specific guests, resulting in the formation of supramolecular polymeric materials. These materials can further be utilized for diverse applications including gene and drug delivery, selfhealing, adsorbents, adhesives, sensing and soft materials. ${ }^{23-29}$ Highly complicated supramolecular structures, such as supramolecular amphiphiles, supramolecular polymers, and molecular machines, have been successfully developed ${ }^{30-33}$ based on hostguest complexation using the aforementioned macrocycles. Macrocycles can be broadly classified into two categories based on their solubility. Firstly, CD- and CB-based materials, such as nanoaggregates, supramolecular polymers, and hydrogels are mostly explored in aqueous media. ${ }^{34,35}$ Secondly, crown ethers (CEs), calixarenes (CAs), and pillararenes (PAs)-based materials are produced in aqueous as well as organic media. ${ }^{36-38}$ Since the neutral states of the latter macrocycles are insoluble in water, organic solvents have been used to prepare supramolecular polymers and gels from their native states. Further, upon modification of these receptors with more suitable polar substituents, their solubility in water can be enhanced, and the resulting amphiphilic polymers involved in the self-assembly process can produce nanoaggregates in aqueous solution.

Over the years, various neutral and charged organic molecular/ polymeric guests have been successfully synthesized, which exhibit high selectivity and good binding affinity towards macrocyclic hosts. ${ }^{39-43}$ The binding affinity of the host-guest complexations can be fine-tuned by various stimuli-responsive factors, such as light, enzyme, redox, $\mathrm{pH}$, temperature, reactive oxygen species (ROS), and ions. Thus, based on the variety of stimuli-responses and the mode of reversibility of the host-guest interactions, MPs can be specifically designed and constructed towards intended applications. In the present review, the cutting-edge research on the construction of various MPs by the supramolecular approach is highlighted. The noncovalent interactions between side-chain polymeric hosts and/or guests, with various applications are discussed in detail. However, the topics related to the discussion of linear polymers and post-polymerizations, and their roles in fabricating MPs are excluded. The construction of MPs with their cores built upon five important macrocyclic hosts, namely CEs, CDs, CAs, CBs, and PAs, is the main focus. Discussions on MPs-controlled topological structures achieved by various facile chemical routes and the functioning of MPs in bulk materials are presented. ${ }^{44,45}$ The main theme of this review includes the construction of MPs by host-guest complexation and their applications in the fields of drug delivery, construction of hydrogels, development of self-healing materials and adhesive materials, as well as some other successful applications, including ionic conductivity, molecular recognition, adsorbent/separation, and smart windows. This review also covers the current challenges that should be considered for the efficient construction of MPs. Such discussions enliven the understanding of the reader and strengthen some of the fundamental concepts governing the construction of MPs, which would provide some clues and new directions for researchers in the fields of supramolecular and materials chemistry.

\section{Crown ether-based MPs}

Crown ethers (CEs) are comprised of a ring with various ether groups and were the first generation of synthetic macrocycles, known to be the birth of supramolecular chemistry. ${ }^{46}$ These macrocycles were developed by the cyclization of polyether units, which consist of more than two ' $\mathrm{O}$ ' atoms with two or more ' $\mathrm{C}$ ' atoms around each ' $\mathrm{O}$ ' atom. These multi-dentate macrocycles exhibit a strong interaction with various guests, while the macrocycles containing ' $O$ ' atoms facilitate the resulting polarity and H-bonding. ${ }^{47,48}$ Most of the CEs, such as 12-crown-4 and 15-crown-5 are water-insoluble, while some of the water-soluble CEs, such as 18 -crown-6, and 24-crown-8 display weak interactions with guests. Such weak interactions may be attributed to the presence of water molecules that limit the ion-dipole interaction between the CEs and guests. It may further be noted that water-soluble CEs alter their critical entropy level from the flexible to less pre-arranged polyether units. CEs-based flexible chains are well-known ionophores that can easily bind with several metal ions while exhibiting less toxicity to anti-parasitic, antibacterial, and anti-cancer treatments. ${ }^{49}$ Moreover, supramolecular interactions between CEs and different guests (secondary ammonium salts and paraquat derivatives) have been utilized for the fabrication of supramolecular nanostructures. During this decade, based on CEs derivatives, various fascinating topological structures, which include supramolecular polymers, 
amphiphiles, rotaxanes, polypseudorotaxanes, and catenanes, have been developed. However, investigations on CEs-based polymeric self-assemblies are few. Therefore, the construction of CEsfunctionalized supramolecular self-assemblies driven by polymeric CEs with electron-withdrawing guests is essential and remains a serious challenge to the modern scientific community.

In 2010, Chen and Wang et al. ${ }^{50}$ developed supramolecular dendritic polymers from the polymeric crown ethers (pCE) and three different protonated ammonium guests (G1-G3). The reversible self-assemblies of dendritic polymers were achieved by the addition of trifluoroacetic acid (TFA) or triethylamine (TEA) (Fig. 2). The percentage of guest (G1) complexation with pCE was estimated to be around $90 \%$ and declined to $85 \%$ after three cycles; these results are quiet similar to G2 and G3. On further comparison with coil polymers, it was observed that dendronized polymeric chains more facilely access guest motifs as compared to coil polymers. Generally, amine-functionalized fluorophores acting as guests usually cause fluorescence quenching of the system due to the intramolecular charge transfer (ICT) process. Therefore, the amino group was protected in the respective guests and recovered the fluorescence. The protonation/deprotonation of the guests on the supramolecular complexes was achieved by TFA/TEA titration experiments. This approach has been adopted by many research groups involved in the preparation of supramolecular polymeric gels by CEs-functionalized monomers/copolymers crosslinking with monomeric/dimeric secondary ammonium salts. Hence, the prepared CEs functionalized polymeric gels were investigated for their self-healing properties and stimuli-responsiveness under different stimuli such as cation, anion, and $\mathrm{pH}$-changes. ${ }^{16}$ Han et $a l .{ }^{51}$ constructed thermo- and ion-responsive supramolecular hydrogels by incorporating CEs into the poly( $N$-isopropylacrylamide) (PNIPAM) polymer. The swelling ratio (SR) of the copolymeric hydrogel was decreased in comparison to the pristine PNIPAM. When the hydrogel was further exposed by
$\mathrm{K}^{+}$ion, the SR of the hydrogel increased considerably in comparison to that in aqueous solution, owing to the ion recognition ability of CEs.

\section{Cyclodextrins-based MPs}

Cyclodextrins ( $\alpha-, \beta-$, and $\gamma-\mathrm{CD})$ are a family of cyclic oligosaccharides that consist of D-glucose linked by $\alpha$-1,4-glucosidic units, comprised of 6 to 8 D-glucopyranose residues. The toroidal shape of CDs has primary hydroxyl groups in the lower end with a reduced cavity size diameter as compared to secondary hydroxyl groups in the upper end. The bristling hydroxyl groups present at the outer cavity were more polar, while the inner cavity exhibited a nonpolar nature. This mixed nature of the outer polar and inner nonpolar cavity engenders a suitable environment for accommodating various guests, such as azobenzene (AZO), phenyladamantane (Ph-ADA), adamantane (ADA), cholesterol, lithocholic acid (LA), ferrocene (Fc), and so on. ${ }^{52-60}$ Moreover, CDs have not only been used for host-guest complexations, they have also been employed as outstanding building blocks to fabricate supramolecular self-assembled nanomaterials. ${ }^{61}$ Different CDs have specific properties to form inclusion complexes with target guests and these abilities predominantly depend on the cavity size of the CDs. ${ }^{62}$ For instance, dodecyl guests can form different stoichiometric complexes with $\alpha-\mathrm{CD}, \beta-\mathrm{CD}$, and $\gamma-\mathrm{CD}$, respectively, which further cause a reduction in the cavity size. Ph-ADA showed better binding affinity $\left(7.6 \times 10^{5} \mathrm{M}^{-1}\right)$ with $\beta$-CD in comparison to $\mathrm{ADA}\left(0.4 \times 10^{5} \mathrm{M}^{-1}\right)$ since the hydrophobic Ph-ADA can gain more control over $\beta$-CD with stronger binding interactions. ${ }^{63}$ The nature of the binding interactions and their reversible assemblies can be regulated by external stimuli ( $\mathrm{pH}$, light, and redox) and competitive hosts/ guests. These approaches have been generically applied to

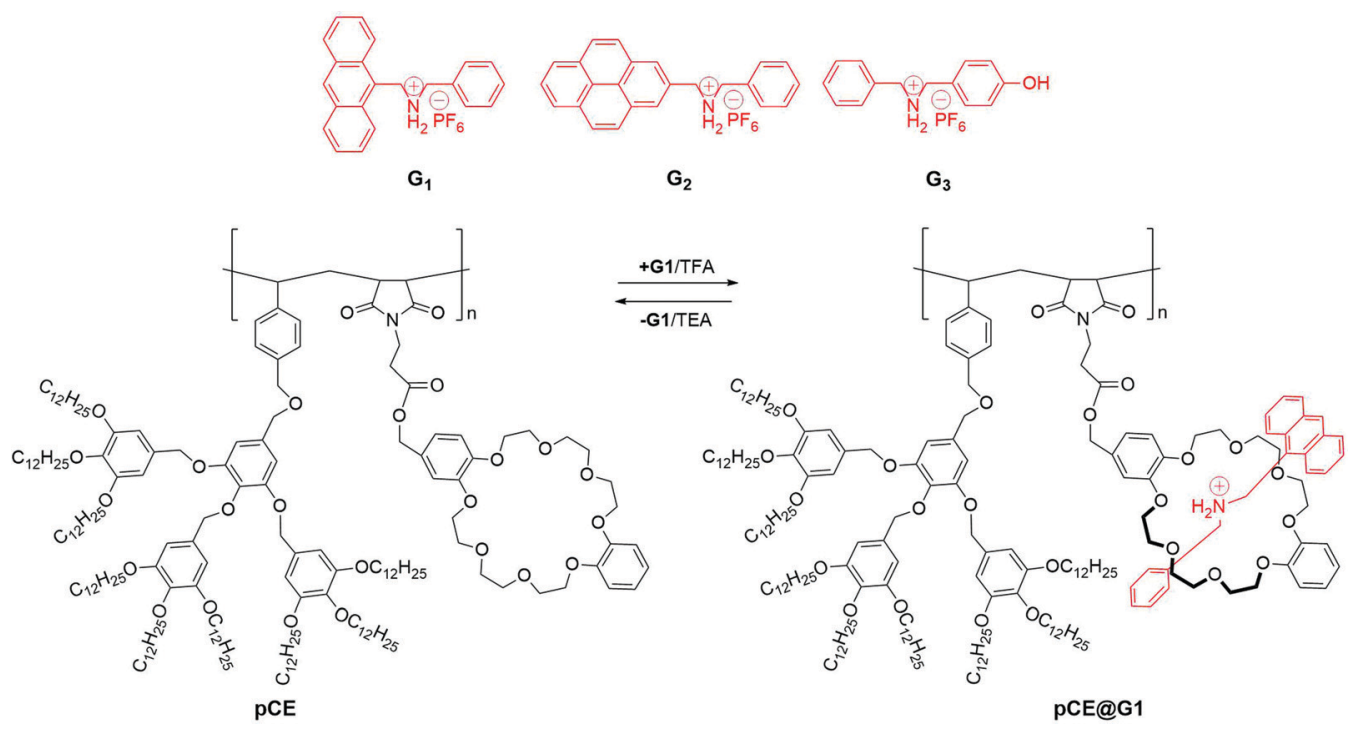

Fig. 2 Structures of G1, G2, G3 and PCE, and the reversible supramolecular self-assembly of dendronized copolymer pCE with mono-valent G1. Reproduced from ref. 50 with permission from John Wiley \& Sons, Inc., Copyright 2010. 
fabricating various kinds of MPs with excellent embedded functionalities.

\subsection{Adamantyl derivatives as guests for the construction of CD-derived polymeric assemblies}

Molecular recognition-based self-assemblies are achieved at the molecular level and a similar mechanism at the macroscopic level is extremely hard to realize due to weaker selective interactions. Inspired by this approach, Harada et al. ${ }^{64}$ developed a well-defined macroscopic assembly using CD-functionalized polymeric gels $(\alpha-\mathrm{CD}$ and $\beta$-CD) with different hydrocarbonderived polymeric guests (adamantyl (Ad) (G4), $n$-butyl ( $n$-Bu) (G5), and $t$-butyl ( $t$-Bu) (G6), respectively) (Fig. 3). Interestingly, they demonstrated that the polymeric host and guest gel pieces could selectively adhere alternately on their surfaces via size- and shape-selective molecular host-guest interactions, producing macroscopic structures with sizes ranging from millimeter $(\mathrm{mm})$ to centimeter $(\mathrm{cm})$. For example, pieces of gels $(\alpha-\mathrm{CD}$, $\beta$-CD, G5 and G6) were mixed and shaken in water, producing the specific ordered macroscopic assemblies $(\alpha$-CD stuck to G5 $\left(K_{\mathrm{a}}=5.7 \times 10^{1} \mathrm{M}^{-1}\right)$, and $\beta$-CD stuck to $\left.\mathbf{G 6}\left(K_{\mathrm{a}}=1.7 \times 10^{2} \mathrm{M}^{-1}\right)\right)$. Similarly, $\beta$-CD and $\mathbf{G 4}$ were adhered to form large aggregates, and there were no interactions with the same pieces of gels, revealing that host-guest interactions could occur at the molecular level as well as at the macroscopic level. G4 had a better

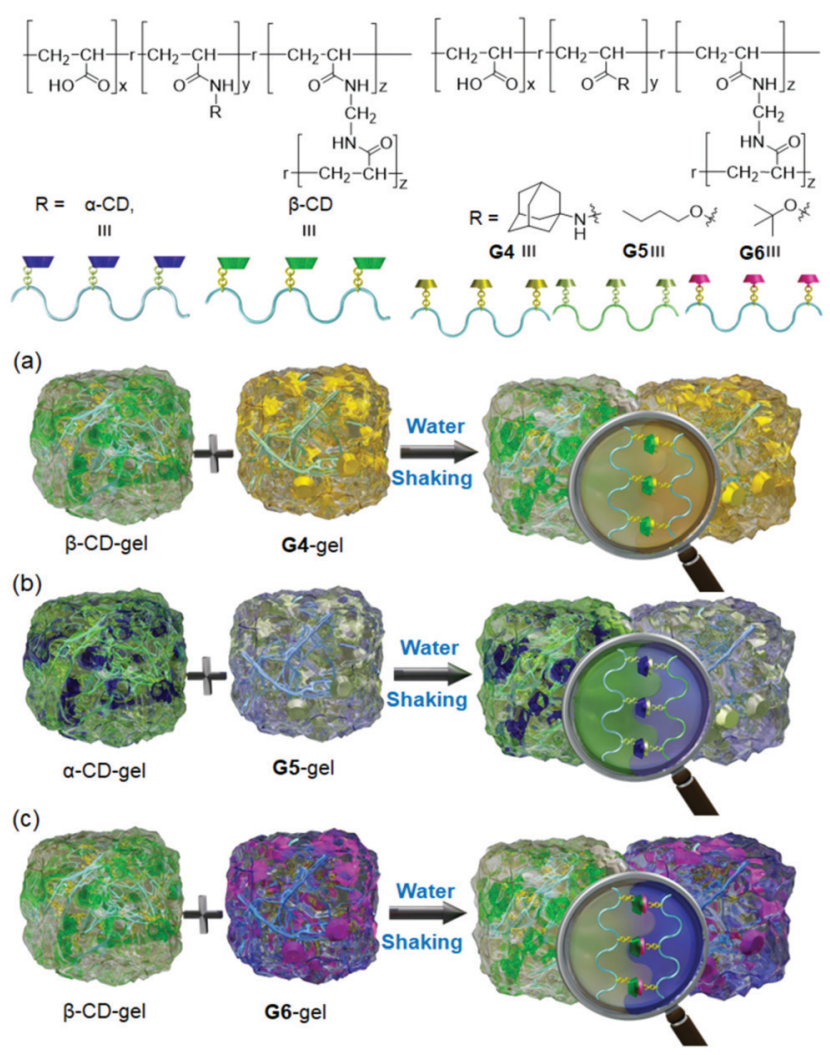

Fig. 3 Chemical structures and graphical representations of $\alpha-C D, \beta-C D$, G4, G5 and G6, and the macroscopic alternative self-assembly of (a) $\beta$-CD-gel contacts with G4-gel; (b) $\alpha$-CD-gel contacts with G5-gel; (c) $\beta$-CD-gel contacts with G6-gel. ${ }^{64}$ binding affinity with $\beta$-CD $\left(K_{\mathrm{a}}=1.5 \times 10^{3} \mathrm{M}^{-1}\right)$ than $\alpha$-CD $\left(K_{\mathrm{a}}=9.8 \times 10^{1} \mathrm{M}^{-1}\right)$, and their reversible assemblies were achieved at high temperature $\left(90{ }^{\circ} \mathrm{C}\right)$ with soluble competitive hosts/guests.

Bernard and Stenzel et al. ${ }^{65}$ reported the fabrication of comb-shaped supramolecular polymers via Ad-end-functionalized reversible addition-fragmentation chain transfer (RAFT) agent and $\beta$-CD-grafted polymers in aqueous media, and their reversible assembly was achieved by competing host analysis. Becer et al. ${ }^{66}$ prepared a thermoresponsive triblock copolymer by RAFT polymerization. This polymer could form inclusion complexes with mono- and hepta-mannosylated-CDs to further assemble into stable micelles ( $T>$ LCST (lower critical solution temperature)) covered with high carbohydrate density. These micelles were further utilized for the binding of concanavalin A (Con A) without affecting the micelle bilayer, but the micelle structure was disassembled by adding competitive CD or lectin. In 2018, both Ad- and Fc-containing stimuli-responsive block copolymers (BCP) were prepared by $\mathrm{Gu}$ et $a{ }^{67}{ }^{67}$ Supramolecular self-assembled micelles were prepared by mixing BCP and $\beta$-CD (equimolar to Ad units), and the obtained micelles were responsive to redox-controlled reversible assembly by using $\mathrm{FeCl}_{3}$ as an oxidant and GSH as a reductant in water. Moreover, oxidation-triggered benzocaine (BA) release (in vitro) from the BA-loaded spherical micelles (encapsulation efficiency $=4.3 \%$ ) was observed in a slow and durable manner (50\%, $40 \mathrm{~h}$ ). Similarly, a poly(norbornene)based BCP side-chain comprised of Ad and $n$-Bu was achieved by ring-opening metathesis (ROMP) and supramolecular selfassembled micelles were obtained via host-( $\beta$-CD)-guest (BCPs) complexations. ${ }^{68}$

\subsection{Azobenzene derivatives as guests for the construction of CD-derived polymeric assemblies}

Photoresponsive supramolecular hydrogels have been constructed with the help of photo-functional structural transformations of azobenzene guests with CDs through non-covalent interactions. Harada et al. ${ }^{69}$ prepared both a curdlan-functionalized $\alpha$-CD and an azo-derivative-functionalized side-chain polymer (G7), for the formation of a cross-linked supramolecular hydrogel ( $\alpha$-CD@G7) $(1: 1)$. Upon irradiating the formed hydrogels with UV light (365 nm), the trans-isomer was converted into the cis-isomer of the azo-polymer (trans/cis = 12:88), and the supramolecular hostguest complexation was demolished. Thus, reversible gel-sol phase changes were observed by the irradiation of light $(365 \mathrm{~nm} /$ $430 \mathrm{~nm}$ ) or by heating (Fig. 4). Similarly, Zhang et al. ${ }^{70}$ reported that $\beta$-CD mediated supramolecular self-assembled spherical micelles ( $\beta$-CD@Azo) and their reversible assemblies were achieved by light irradiation (UV/visible, $30 \mathrm{~min}$ ).

Red- and near-infrared (NIR) light-responsive supramolecular assemblies are more efficient than the UV-responsive ones. Therefore, $\mathrm{Wu}$ et al. ${ }^{71}$ constructed red-light-responsive supramolecular hydrogels by the combination of both tetra-orthomethoxy-substituted azobenzene (mAzo) and $\beta$-CD-functionalized polymers, and reversible assemblies (gel/sol) were obtained by red/ blue $(625 \mathrm{~nm} / 470 \mathrm{~nm})$ light irradiation (30 min). Furthermore, this hydrogel was utilized as a protein (bovine serum albumin (BSA)) carrier and red-light assisted controlled protein release 


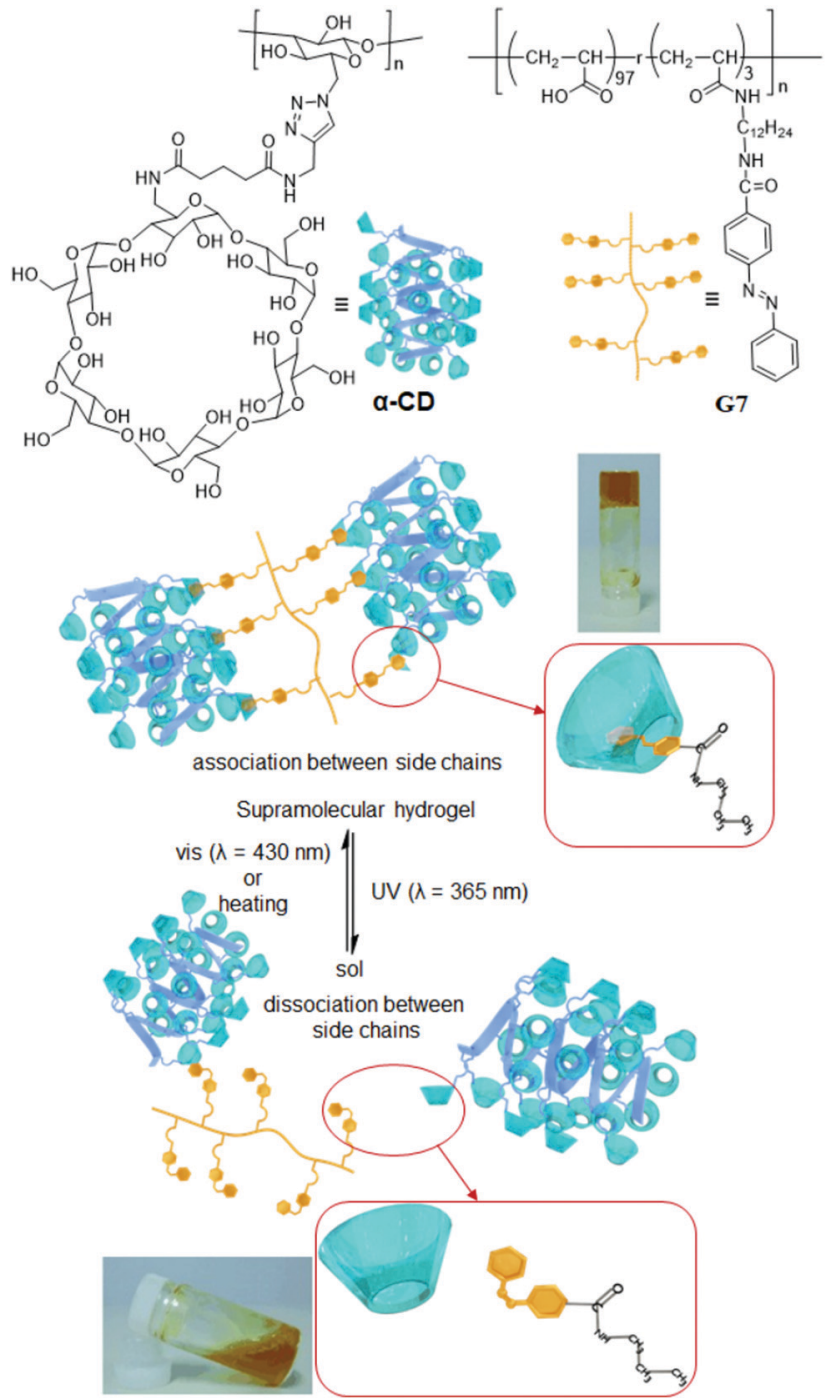

Fig. 4 Structures and schematic representation of the interactions of the $\alpha-C D$ (cylindrical shapes) with G7 (yellow shapes) upon irradiation with UV $(365 \mathrm{~nm})$ and visible light $(430 \mathrm{~nm})$ or heating at $60{ }^{\circ} \mathrm{C}$. Reproduced from ref. 69 with permission from John Wiley \& Sons, Inc., Copyright 2010.

$\left(\sim 83 \%, 60 \mathrm{~min}, 60 \mathrm{~mW} \mathrm{~cm}^{-2}\right)$ from the gel was observed in deep tissue. An alternative approach was introduced by Armes and Tian $e t$ al. ${ }^{72}$ in which the rate of thermo-responsive supramolecular morphological changes from vesicles to worms and/or spheres $\left(20\right.$ to $\left.2{ }^{\circ} \mathrm{C}\right)$ could be achieved by host-guest interactions between $\beta$-CD-functionalized BCP and azobenzene-linked mPEG (methoxy polyethylene glycol). The rate of morphological transitions was faster in the case of supramolecular vesicles $\left(d=100 \mathrm{~nm}, 70 \mathrm{~min}\right.$ at $\left.2{ }^{\circ} \mathrm{C}\right)$ owing to its reduced geometric packing of the supramolecular assemblies as compared to the $\beta$-CD-functionalized vesicles alone $\left(d=340 \mathrm{~nm}, 300 \mathrm{~min}\right.$ at $\left.2{ }^{\circ} \mathrm{C}\right)$.

\subsection{Ferrocene derivatives as guests for the construction of CD-derived polymeric assemblies}

Ferrocene-based supramolecular materials have dual functionalities, i.e., a redox switching and self-healing nature. Inspired by the above functions, Harada et al. ${ }^{73}$ designed the supramolecular hydrogels ( $\beta$-CD@G8) composed of multiple crosslinking between poly(acrylic acid)-functionalized $\beta$-CD and ferrocene (G8) polymers, which further produced the redox switching (sol-gel) and self-healing materials (re-adhesion) (Fig. 5). The $\beta$-CD@G8 hydrogel showed the highest elasticity (176 Pa) as compared to other combinations $(<50 \mathrm{~Pa})$, and the reduced form of Fc showed higher affinity for $\beta-\mathrm{CD}$, due to its hydrophobic property, in comparison with the oxidized form $\left(\mathrm{Fc}^{+}\right)$. For reversible assembly (gel to sol), a competitive host ( $\beta$-CD (excess))/guest (Ad) was used to cut off/rejoin the $\beta$-CD@G8 hydrogel (recovered strength $=84 \%, 24 \mathrm{~h}$ ). Similar work on the construction of redox switchable supramolecular graft polymers via host-guest complexation between Fc-copolymers and end-chain functionalized $\beta$-CD polymer was reported by Ritter and BarnerKowollik et al. ${ }^{74}$ In this system, the host-guest assembly in aqueous solution produced mono- and multi-core micelle-aggregates $(d=$ $10 \mathrm{~nm}$ and $300 \mathrm{~nm}$ ) and the reversible assembly/disassembly could be easily achieved by redox reactions (cyclic voltammetry (CV)) and a competing guest (potassium 1-adamantylcarboxylate (Ad-COOK)).
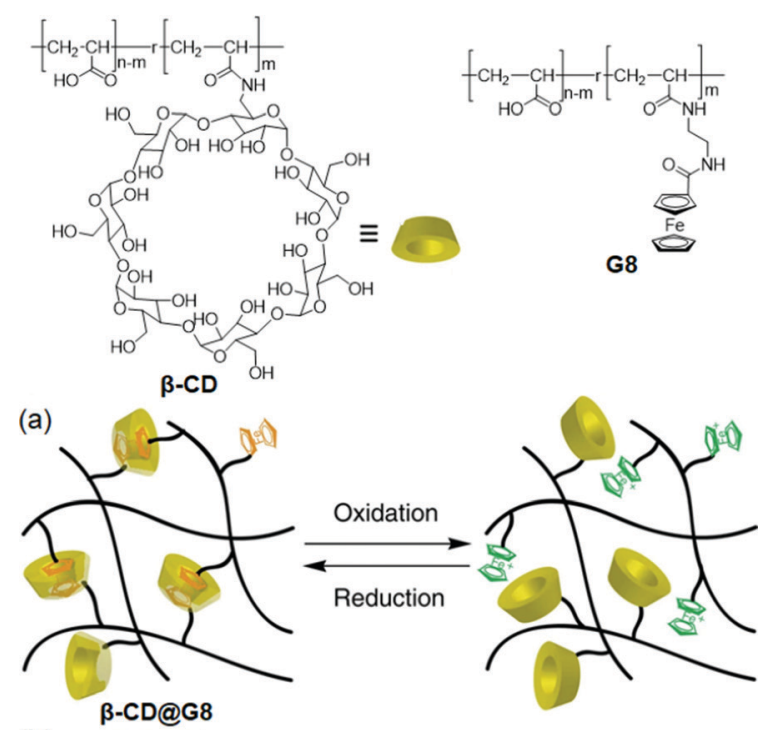

(b)


Gel

(c)
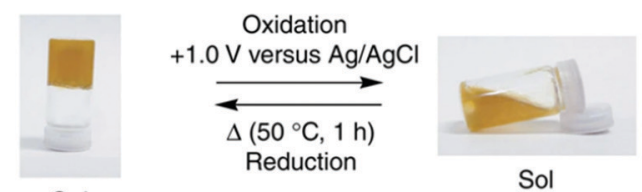

Gel

Fig. 5 Structures of $\beta-C D$ and $\mathbf{G 8}$, and redox-responsive $\beta$-CD@G8 hydrogels. (a) Schematic illustration of $\beta-C D @ G 8$ complexation. (b) Solgel transition (chemical reagents). (c) Sol-gel transition experiment using electrochemical reactions. Electrochemical oxidation $(+1.0 \mathrm{~V}$ versus $\mathrm{Ag} / \mathrm{AgCl}$ ). Reproduced from ref. 73 with permission from the Nature Publishing Group, Copyright 2011. 


\subsection{Other derivatives as guests for the construction of CD-derived polymeric assemblies}

The visual recognition of the supramolecular self-assemblies in aqueous solutions is an interesting phenomenon in supramolecular chemistry. Ritter and Barner-Kowollik et al. ${ }^{75}$ prepared supramolecular graft polymers via $\beta$-CD end-functionalized polymeric host interactions with phenolphthalein-based polymeric guests. Upon complexation of $\beta$-CD with phenolphthalein, the pink color of phenolphthalein changed to colorless and its absorption band (560 $\mathrm{nm}$ ) gradually decreased upon increasing the $\beta$-CD concentrations ( 1 to 100 equiv.) in basic media. This is probably because of the re-lactonization of the phenolphthalein moiety in the brush-like supramolecular assembly.

To enhance the anticancer efficiency, drug solubility was improved by encapsulating the drugs within the $\beta$-CD cavity. Thus, Kim et al. ${ }^{76}$ developed a stable nano-assembly based on polymeric $\beta$-CD (pCD) and polymeric paclitaxel (pPTX) via multivalent host-guest complexation between pCD and pPTX. In comparison, the multivalent pCD@pPTX binding interaction was higher $\left(10^{4}\right)$ than the monovalent paclitaxel (PTX)/ $\beta-C D$ interaction, which extended the blood passage time and hindered the early drug release. Activator protein 1 (AP-1) with efficient targeting effects towards the interleukin-4 receptor was then incorporated into the fabricated supramolecular nano-assembly, making the nanomedicine (AP-1-pCD@pPTX) able to precisely release PTX to MDA-MB-231 cells via receptorassisted endocytosis (Fig. 6). In this system, PTX was linked to the building blocks of the polymer via ester bonds, which is responsible for the successful drug delivery by enzymatic degradation in cells. AP-1-pCD@pPTX could considerably suppress tumor growth and improve the survival rate of tumorbearing mice. The anticancer efficiency of this nanomedicine was increased as compared to that of the currently available (Taxol), playing a vital role in cancer treatment.

A thermoresponsive supramolecular system was constructed by Zhu et al. ${ }^{77}$ through noncovalent interactions between cholic



Fig. 6 Structures and schematic illustrations of the AP-1- $\beta$-CD@pPTX nano-assembly-assisted paclitaxel (PTX) drug delivery. ${ }^{76}$

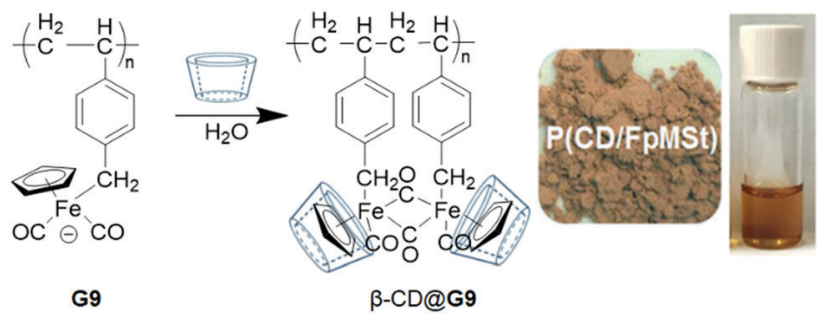

Fig. 7 Preparation of $\beta$-CD@G9 and the photographs of the solid and solution (DMSO). Reproduced from ref. 79 with permission from John Wiley \& Sons, Inc., Copyright 2017.

acid functionalized copolymer $(\mathrm{CA})$ and $\beta-\mathrm{CD}\left(K_{\mathrm{s}}=4.07 \times 10^{3} \mathrm{M}^{-1}\right)$ and the phase transition temperature of this system could be reversed by the addition of a competing guest (K-Ad, $K_{\mathrm{s}}=3.98 \times$ $\left.10^{4} \mathrm{M}^{-1}\right)$. They further fabricated a supramolecular hydrogel $(\beta-\mathrm{CD} @ \mathrm{CA})^{78}$ by mixing water-soluble CA and $\beta$-CD copolymers, and the stability of this hydrogel was increased (cross-linking density) at a high molar fraction of $\mathrm{CA}\left(\mathrm{G}^{\prime}=217 \mathrm{~Pa}\right.$ at $8.3 \mathrm{wt} \%$, $[\mathrm{CA}] /[\beta-\mathrm{CD}]=1)$. The dynamic reversible assembly of the hydrogel (gel-sol) was further evaluated by adding a competing guest (K-Ad), as well as by heating.

Wang et $a .^{79}$ developed an alternative approach for the preparation of an air-stable supramolecular complex (solid/solution) through the complexation of the air-sensitive $\mathrm{CpFe}(\mathrm{CO})_{2}(\mathrm{Fb})$ pendant-containing polymer (G9) with $\beta$-CD. The formed $\beta$-CD@G9 complex produced an intramolecular dimerization with the nearby Fp pendant, exhibiting improved stability (Fig. 7). In contrast, the $\beta-\mathrm{CD} @ \mathbf{G 9}$ decomposed upon the removal of $\mathrm{CD}$ via the competing guest (Ad-COOH). Interestingly, this metal complex system exhibited a high response towards light (LED) and could thus be successfully utilized for CO release and antimicrobial materials.

\section{Calixarene-based MPs}

Calix $[n]$ arenes (CAs) and their functionalized derivatives consist of phenolic rings attached via methylene bridges, and they possess distinctive conformations and cavities to accommodate various guests. ${ }^{80}$ In particular, $\mathrm{CA}[4]$ is one of the well-known macrocycles in supramolecular chemistry, and various analogous of macrocycles (oxacalixarenes, thiacalixarenes, azacalixarenes, calixpyrrole, etc.) have been synthesized by replacing the methylene bridges with some other units. Well-defined structural modifications of CAs have been employed as specific hosts for the recognition of target guests and have been utilized for various applications. ${ }^{81}$ CAs-functionalized polymers have played a vital role in the construction of supramolecular self-assemblies due to its rigid structure, producing highly ordered nanostructures with enhanced stability. ${ }^{82}$ To enhance their sustainability, water-soluble CAs were developed with suitable substituent groups (ammonium, phosphate, sulfonate, peptide, etc.) on the upper rim, which could be used as templates for the fabrication of various MPs nanoarchitectures by interacting with hydrophobic guests in aqueous media. ${ }^{83}$

In 2010, Haino et al. ${ }^{84}$ developed a supramolecular crosslinked assembly $\left(M_{\mathrm{n}}=32000, \mathrm{PDI}=2.81\right.$ at 0.5 equiv. of CA $)$ by 

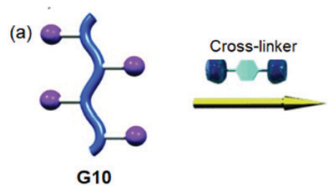

(b)

$\mathrm{fCH}=\mathrm{C})_{x}(\mathrm{CH}=\mathrm{C})_{y}$

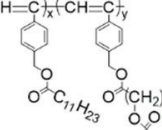

G10

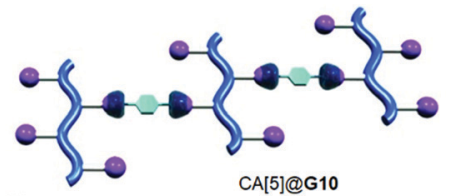

CA[5]@G10

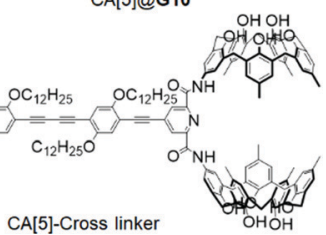

Fig. 8 (a) Illustrations of the supramolecular cross-linking of CA[5] @ G10 by host-guest interactions between G10 (pink spheres) and CA[5]. (b) Structures of G10 and CA[5]. Reproduced from ref. 84 with permission from John Wiley $\&$ Sons, Inc., Copyright 2010.

using a fullerene (C60) grafted polymer (G10) $\left(M_{\mathrm{n}}=13000\right.$, PDI = 1.38) and CA[5]-functionalized homoditopic cross-linker (interchain manner) as shown in Fig. 8. Their noncovalent cross-linking stability was evaluated in different solvents (toluene $>$ chloroform $>o$-dichlorobenzene). G10 showed a particle-like morphology $(d=10-30 \mathrm{~nm})$, which changed into an ordered fibrous network structure (pitch $=19.6 \pm 1.6 \mathrm{~nm}$ ) of the cross-linked CA[5]@G10. A few research groups ${ }^{85-87}$ also reported the preparation of $\mathrm{CA}[4]$-based polymeric derivatives, which were further used as resin/adsorbent materials for the selective recognition and removal of toxic heavy metal ions $\left(\mathrm{Pb}^{2+}, \mathrm{Cu}^{2+}, \mathrm{Cd}^{2+}, \mathrm{Hg}^{2+}, \mathrm{Co}^{2+}\right)$ and alkali metals $\left(\mathrm{Na}^{+}, \mathrm{K}^{+}, \mathrm{Cs}^{+}\right)$in aqueous solution.

Aseyev et al. ${ }^{88,89}$ synthesized photo-responsive poly(azocalix[4]arene)s that were functionalized with different alkyl/tetraethylene glycol chains on the lower rim, and studied their dynamic host-guest interactions with different alkyl chainsubstituted pyridinium guests, respectively. To increase the sustainability, Taylor et al..$^{90}$ prepared a water-soluble supramolecular polymeric system from a sulfonated $\mathrm{CA}[4]$ polymer and methyl viologen $\left(\mathrm{MV}^{2+}\right)$ guest via non-covalent interactions, and examined their fluorescence and electrochemical stimuliresponsiveness.

In 2014, Sessler and Bielawski et al. ${ }^{91}$ reported the preparation of a calix[4]pyrrole-functionalized copolymer, which could form a supramolecular cross-linking gel with dianionic guests such as bis(TBA) terephthalate (TBA) 2 TPA, and tris(TBA) hydrogen pyrophosphate (TBA) ${ }_{3} \mathrm{HP}_{2} \mathrm{O}_{7}$ (as tetrabutylammonium (TBA) salts). Furthermore, this gel material could be utilized for the separation/extraction of dianions ((TBA) $)_{2}$ TPA $(13 \%)$ and $(\mathrm{TBA})_{3} \mathrm{HP}_{2} \mathrm{O}_{7}$ $(10 \%))$ from aqueous solution. Sessler and coworkers ${ }^{92}$ reported that a calix[4]pyrrole-based copolymer (C4P) led to the formation of micelles $\left(d=45 \mathrm{~nm}, 1 \times 10^{-4} \mathrm{M}\right)$ in aqueous solution, which could be employed to capture cesium anions ( $\mathrm{CsF}, \mathrm{CsCl}, \mathrm{CsBr}$, CsI, and $\left.\mathrm{CsNO}_{3}\right)$ upon heating $\left(50{ }^{\circ} \mathrm{C}\right)$ the solution above its LCST. Interestingly, the formed anion-containing precipitates could be easily separated by filtration and the free anions could be removed on exposure to dilute acid (dil. $\mathrm{HNO}_{3}$ ) (Fig. 9). In particular, $\mathrm{C} 4 \mathrm{P}$ had a preference for removing $\mathrm{CsBr}(39 \%)$ as compared to $\mathrm{CsCl}(32 \%)$ and $\mathrm{CsF}(16 \%)$. In contrast, CsI and

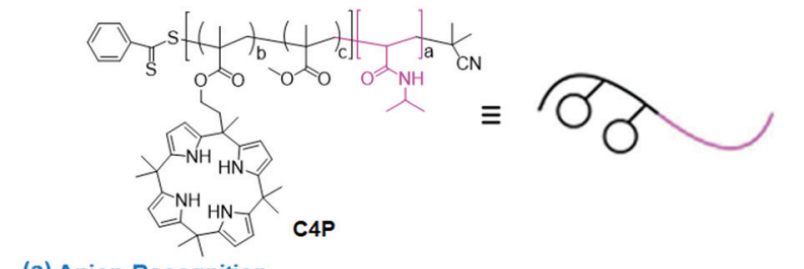

(a) Anion Recognition

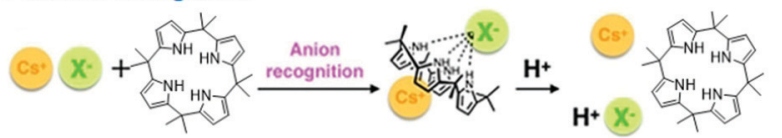

(b) Water Purification

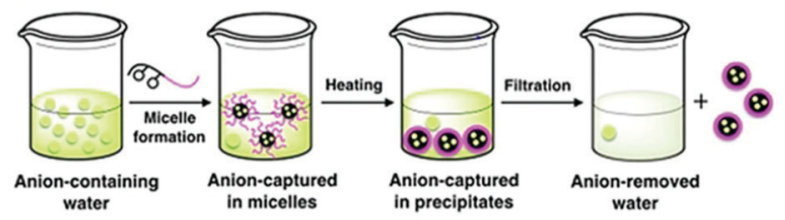

(c) Regeneration

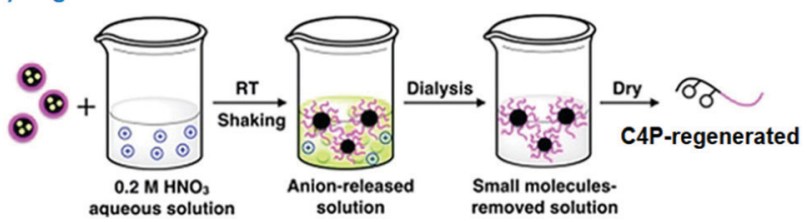

Fig. 9 Structure and schematic representation of the (a) C4P-assisted anion recognition and acid-induced disassembly. (b) Anion removal and (c) regeneration of C4P from aqueous solution. Reproduced from ref. 92 with permission from John Wiley \& Sons, Inc., Copyright 2018.

$\mathrm{CsNO}_{3}$ have weak affinities for poorly hydrated ions and are hard to remove from aqueous solutions. Similar sensing strategies of C4P were also applied to anionic dyes $\left(\mathrm{Cs}^{+}\right.$salts of $\mathrm{ArCOO}^{-}$and $\mathrm{ArO}^{-}$(Ar-Coumarin)) and their removal efficiencies were calculated to be $62.5 \%\left(\mathrm{ArCOO}^{-}\right)$and $48.9 \%\left(\mathrm{ArO}^{-}\right)$, respectively.

In 2016, Huang and Sessler et al. ${ }^{93}$ developed an interesting approach for the fabrication of a 'Texas-sized' molecular box-based supramolecular self-assembly through the host-guest interaction between a Texas-sized (Ts) macrocycle and an anionic polymer (G11) in a monotonic manner (1:1). By tuning the Ts ratio with respect to the anionic G11, various morphologies including tubules, vesicles, fusion (strings of beads), worm-like micelles, and spherical micelles could be obtained as shown in Fig. 10. This supramolecular self-assembled system exhibited responsiveness to both $\mathrm{pH}$ and biological molecules (adenosine- $5^{\prime}$-triphosphate (ATP), adenosine$5^{\prime}$-diphosphate (ADP) and adenosine- $5^{\prime}$-monophosphate (AMP)), and it could be further used for various cargo loading/releasing applications in living cells (HUVEC and HepG2 cell lines). Recently, various polymers bearing calix[4]pyrrole and tetracationic 'Texas-sized' molecular box moieties have been applied to extract inorganic and organic anions, and adhesive polymeric materials related applications, which were also highlighted in the reported reviews. ${ }^{94,95}$

\section{Cucurbituril-based MPs}

In 1905, Behrend et al. ${ }^{96}$ first synthesized cucurbiturils (CBs) from acid-catalyzed condensation reactions of urea, glyoxal, 

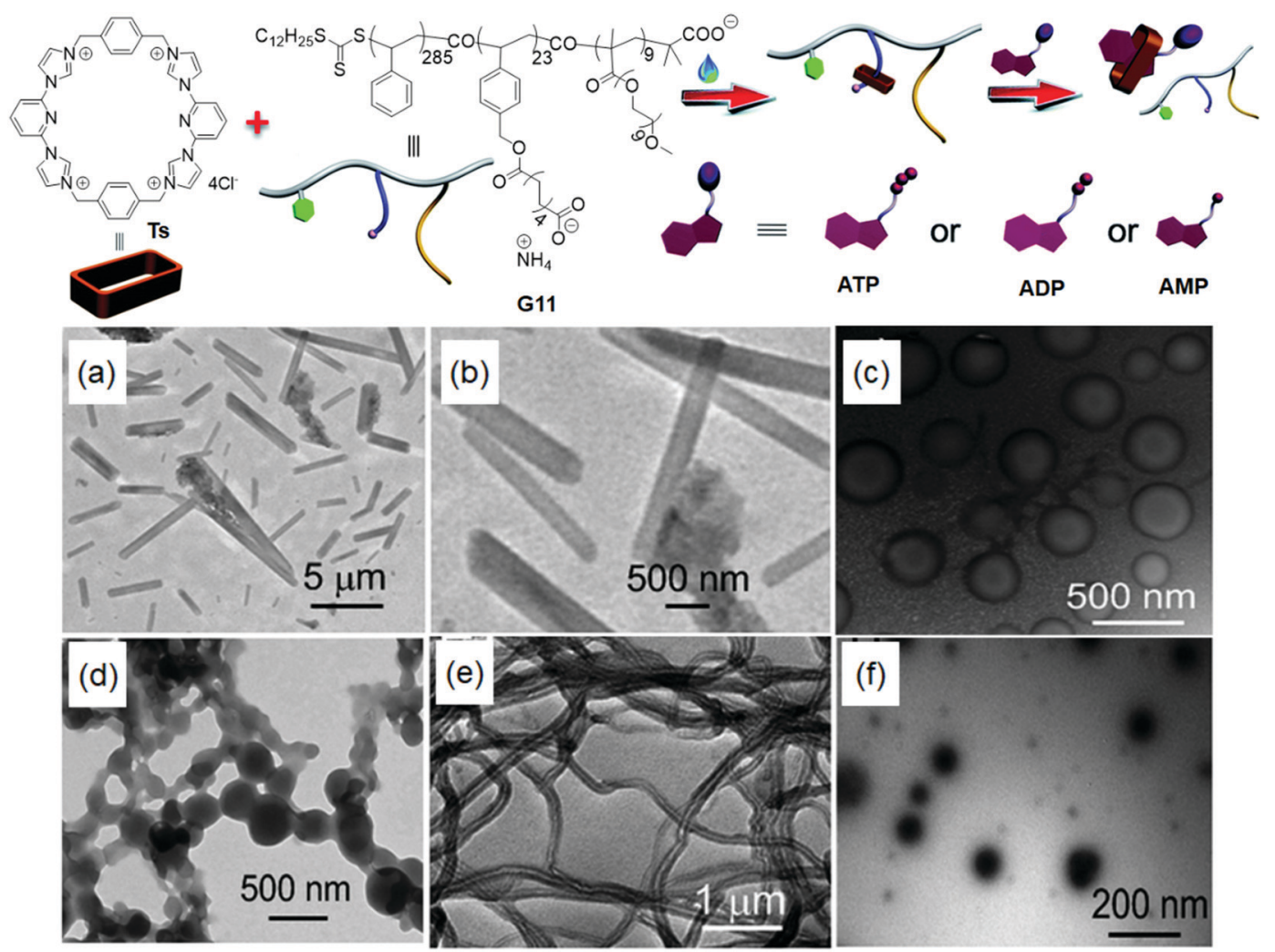

Fig. 10 Chemical structures and graphical illustrations of Ts, G11 and Ts@G11 assemblies, and nucleotides-responsive disassemblies. TEM images of the copolymer G11 (0.100 mM) obtained by tuning the ratios of Ts (mM): (a) 0; (b) enlarged view of (a); (c) 0.500; (d) 1.00; (e) 1.50; (f) 2.30. Reproduced from ref. 93 with permission from the Royal Society of Chemistry, Copyright 2016.

and formaldehyde, and their complete structures were elucidated by Mock and Freeman et al. using X-ray crystallography. ${ }^{97}$ Kim and Day et al ${ }^{98-100}$ synthesized and isolated the homologues of $\mathrm{CB}[n](n=5,7,8$, and 10). In the case of $\mathrm{CB}[5]$ to $\mathrm{CB}[8]$, the cavity diameter increased from $\sim 4.4 \AA$ to $\sim 8.8 \AA$, corresponding to the diameter of the portal $(\sim 2.4 \AA$ to $\sim 6.9 \AA)$. The cavity sizes of CBs resemble that of the cyclodextrin (CD) derivatives $(\alpha-, \beta$-, and $\gamma$-CD), but the symmetric pumpkin-like structure of CBs is far different from the CD derivatives. The CB portals are decorated with electron-rich carbonyl groups, thus CBs can noncovalently interact with various sizes of positively charged/neutral guests to form supramolecular host-guest complexations via hydrogen bonding, charge-dipole, and the hydrophobic/hydrophilic effect. ${ }^{101}$ For example, (i) CB[5] with a smaller cavity can form complexes with larger sized cations $\left(\mathrm{NH}^{4+}\right.$ and $\left.\mathrm{Pb}^{2+}\right)$ by suspending on the portals; ${ }^{102,103}$ (ii) $\mathrm{CB}[6]$ can form inclusion complexes with hydrophobic neutral guests (tetrahydrofuran and benzene), protonated amines (diaminoalkanes $\left(K_{\mathrm{a}}>10^{5} \mathrm{M}^{-1}\right)$ and $p$-methylbenzylamine $\left(K_{\mathrm{a}} \sim 10^{2} \mathrm{M}^{-1}\right) ;{ }^{104-106}$ (iii) $\mathrm{CB}[7]$ can interact with naphthalene, protonated adamantanamine, $\mathrm{MV}^{2+}, \mathrm{Fc}$, and carborane, respectively, thus leading to the formation of $1: 1$ stoichiometric complexes; ${ }^{107}$ (iv) $\mathrm{CB}[8]$, with a large cavity, is involved in the complexation with large-sized guests (cyclen, cyclam, and their respective metal complexes). Interestingly, the larger cavity volume of $\mathrm{CB}[8]\left(479 \AA^{3}\right)$ has been utilized as a "molecular handcuff" to accommodate two guests (electron-deficient and electron-rich) within its cavity to form a stable ternary complex $(1: 1: 1)\left(10^{15} \mathrm{M}^{-2}\right)$ via multiple noncovalent interactions. ${ }^{108,109}$ Due to the unique nature of $\mathrm{CB}[8]$, it has been exploited to construct MPs that have been used for various applications.

In 2010, Scherman et al. ${ }^{110}$ fabricated 3D supramolecular hydrogels by using multivalent copolymeric guests (electronpoor $\mathrm{MV}^{2+}$ and electron-rich naphthoxy (Np) derivatives) crosslinked with $\mathrm{CB}[8]\left(K_{\mathrm{a}}>10^{11} \mathrm{M}^{-2}\right)$. The $1: 1: 1\left(\mathrm{CB}[8]: \mathrm{MV}^{2+}: \mathrm{Np}\right)$ supramolecular ternary complexes were reversible and responsive to external environments (heating or excess $\mathrm{CB}[8]$ ). In continuation of their previous work, Abell and Scherman et $a l .{ }^{111}$ described the formation of supramolecular-assisted microcapsules from ternary complexes of $\mathrm{CB}[8], \mathbf{G 1 2}$ and $\mathbf{G 1 3}$ (1:1:1) by using a microfluidic droplet $(d=59.6 \pm 0.8 \mu \mathrm{m})$ method. After dehydration, these microcapsules had monodispersed AuNPs $(d=5 \mathrm{~nm})$ within the supramolecular complex (Fig. 11), which exhibited surface-enhanced Raman spectroscopy (SERS) signals for $\mathrm{CB}[8]$ and $\mathrm{MV}^{2+}\left(\lambda_{\text {ex. }}=633 \mathrm{~nm}\right)$. This capsule was further used for cargo (FITC-dextran) loading and releasing (sodium dithionite $\left(\mathrm{Na}_{2} \mathrm{~S}_{2} \mathrm{O}_{4}\right)$ ) applications.

Another approach introduced by Ikkala and Scherman et al. ${ }^{112}$ was the construction of cellulose nanocrystal (CNC)-based nanocomposite hydrogels, which were based on the supramolecular cross-linking of the three-component recognition of the CNC bearing Np polymer (G14) with the $\mathrm{MV}^{2+}$-functionalized polymer 

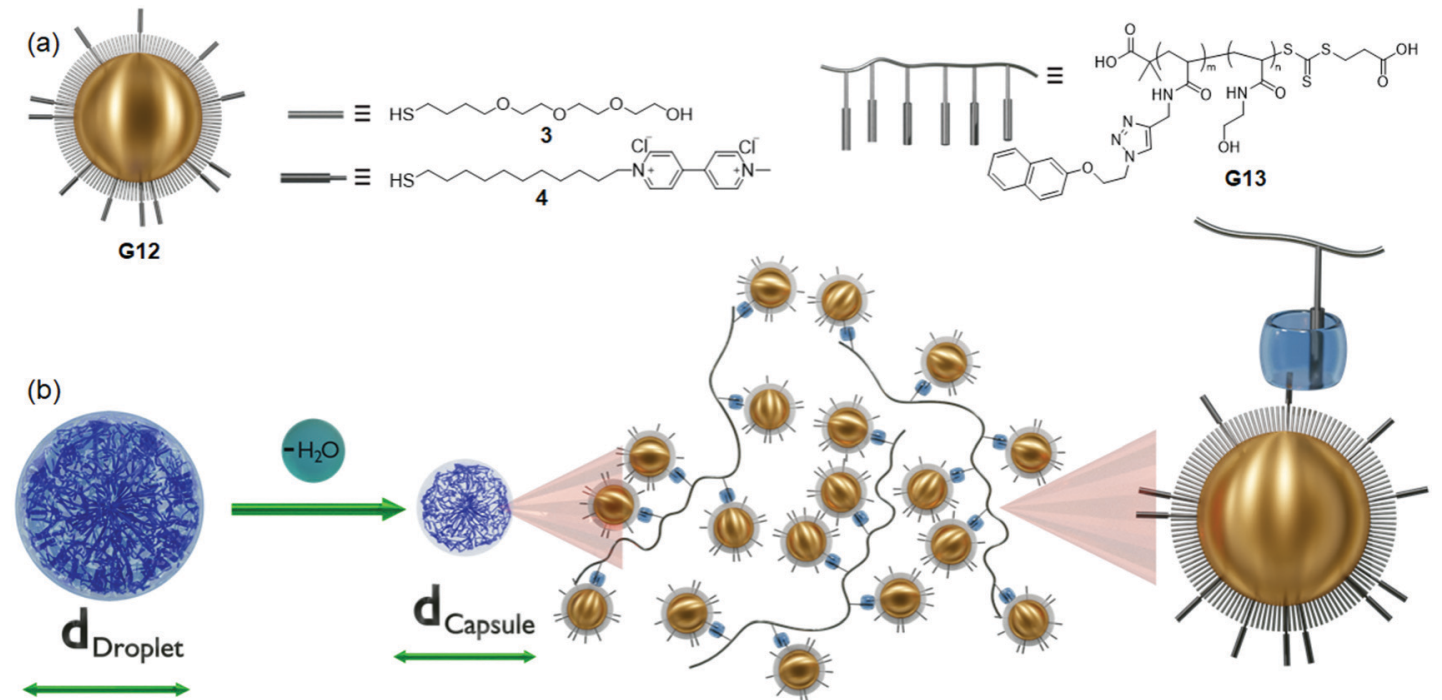

Fig. 11 (a) Schematic representation and structures of the G12 (AuNP functionalized with a mixture of 3 and 4) and G13. (b) Illustration of the microcapsule formation process from the initial droplet stage to the dehydrated stable capsules. ${ }^{111}$

(G15) and $\mathrm{CB}[8]$ in aqueous solution $(\mathrm{pH}=0.5)$. The formed nanocomposite hydrogels showed rapid sol-gel transition $(<6 \mathrm{~s})$, high storage modulus $\left(G^{\prime}>10 \mathrm{kPa}\right)$ and rapid self-healing properties facilitated by reinforced colloidal stability with three-component complexations $(1: 1: 1)$ at lower pH (Fig. 12). Abell and coworkers ${ }^{113}$ prepared supramolecular ternary complex-assisted hydrogel beads through the non-covalent interactions of $\mathrm{CB}[8]$ with $\mathrm{MV}^{2+}$ and $\mathrm{Np}$ by using microdroplets as templates. FITC-dextran (cargo) was loaded on the hydrogel beads and could be potentially utilized for controlled cargo release by adding a competitive guest (1-adamantylamine). Likewise, Cao et al. ${ }^{114}$ fabricated self-healing supramolecular hydrogels by the cross-linking of $\mathrm{CB}[8]$ with naphthaline containing sidechain copolymers to form a ternary complex $(1: 2)$.

The integration of host-guest complexation and polymeric materials was employed for the fabrication of colloids, which could be further used in several applications. ${ }^{115-117}$ For instance, Weck et al. ${ }^{118}$ reported the directional host-guest self-assembly of cyanine dyes-functionalized colloidal particles with telechelic BCPs attached to patchy particles. These colloidal particles could directionally assemble into longer and branched chains based on the selective heteroternary complexation of polymeric guests $\left(\mathrm{MV}^{2+}\right.$ and azobenzene) within the inner cavity of $\mathrm{CB}[8]$. Later, Chen and coworkers ${ }^{119}$ fabricated an amphiphilic supramolecular brush copolymer by the ternary complexation of $\mathrm{CB}[8]$, 4,4'-bipyridinium-functionalized copolymer (G16) and PEGylated $\mathrm{Np}$ (G17). This supramolecular polymer could further selfassemble into supramolecular spherical NPs (SNPs, $d=40 \mathrm{~nm}$ ) with the aggregation-induced emission (AIE) effect. These SNPs were further used for DOX encapsulation (encapsulation efficiency = $11.7 \%$ ) in aqueous solution, while the DOX-loaded SNPs showed (a)

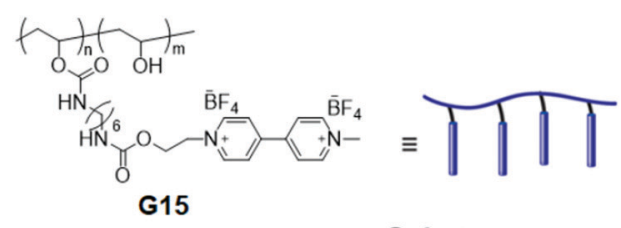

(c)
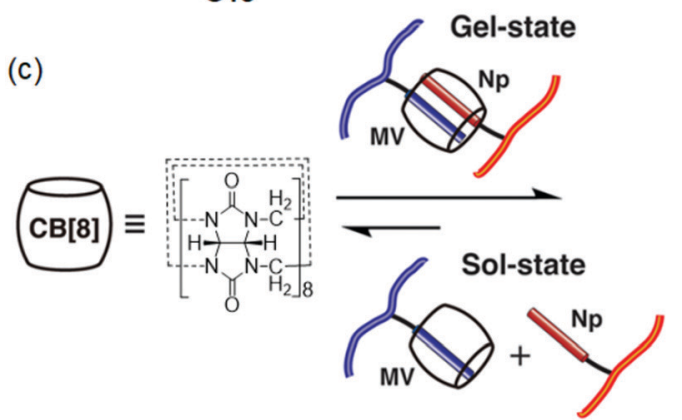

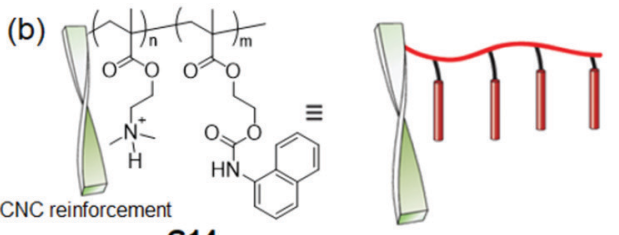

(d)

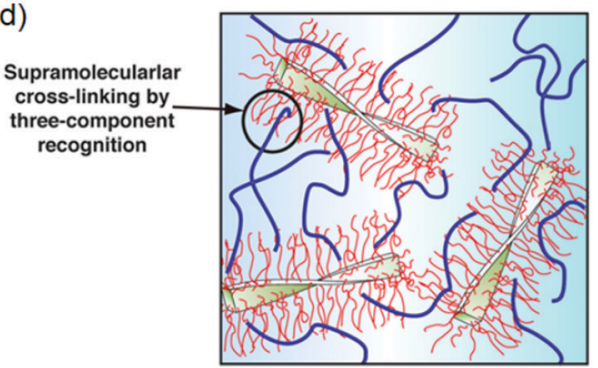

Fig. 12 Chemical structures and graphical representations of the (a) G15, (b) G14, (c) CB[8] and sol-gel transitions; (d) supramolecular cross-linking of the three-component complexation-based dynamic hydrogels (chiral twist of CNC). Reproduced from ref. 112 with permission from John Wiley \& Sons, Inc.; Copyright 2014. 
(a)
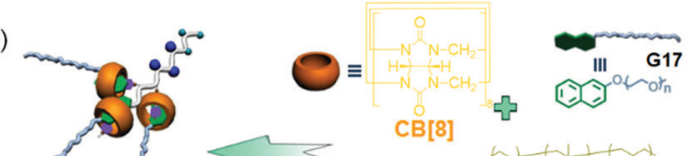

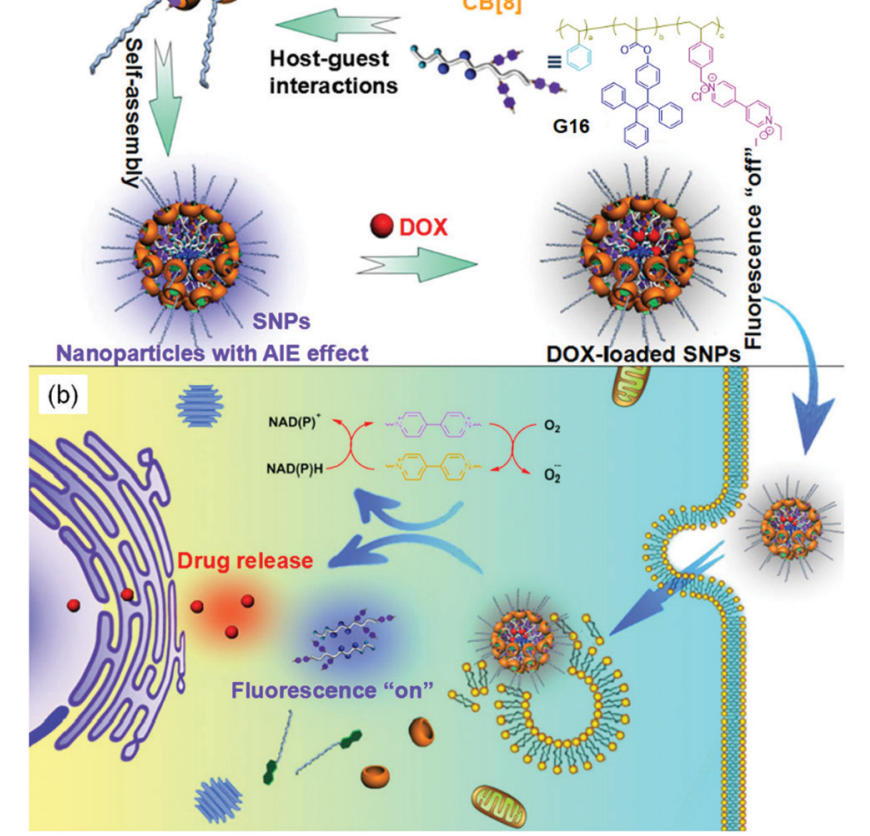

Fig. 13 (a) Chemical structures and schematic representation of $\mathrm{CB}[8]$, G16 and G17, and the preparation of SNPs and DOX-loaded SNPs. (b) Illustration of the imaging-guided drug delivery. Reproduced from ref. 119 with permission from the American Chemical Society; Copyright 2017.

fluorescence switching phenomenon (fluorescence-off) due to the formation of a Förster resonance energy transfer (FRET) system (Fig. 13). Upon adding $\mathrm{Na}_{2} \mathrm{~S}_{2} \mathrm{O}_{4}\left(5 \mathrm{mg} \mathrm{mL}{ }^{-1}\right)$, these DOXencapsulated SNPs exhibited efficient anticancer drug release $(77 \%, 36 \mathrm{~h})$, with a clear observation of the fluorescence turn-on mechanism.
Typically, the branched polymeric topology can modify the chain relaxation, increasing the toughness and mechanical strength of the hydrogels. Based on the above approach, Scherman et al. ${ }^{120}$ stated the fabrication of supramolecular hydrogels from the $\mathrm{CB}[8]$-threaded highly branched polymer (HBP-CB[8]) $\left.\left(M_{\mathrm{w}}=3.0 \pm 1.5\right) \times 10^{6} \mathrm{~g} \mathrm{~mol}^{-1}\right)$ and linear hydroxyethyl cellulose-functionalized naphthalene (G18) (2 wt\% of each). In this system, they abridged the synthetic route from three components to two components via the mechanical locking of $\mathrm{CB}[8]$ into the branched polymeric backbones. Compared with the three-component complexation (G19@CB[8]@G18, weak hydrogel, shear rate $=100 \mathrm{~Pa} \mathrm{~s}$ ), the two-component strategy led to the formation of a strong hydrogel HBP-CB[8]@G18 with high viscosity (shear rate $=2000$ Pa s) (Fig. 14). Briefly, compared with the linear G19@CB[8]@G18, HBP-CB[8]@G18 showed strain hardening due to the crosslinking of the intrachain to the interchain in the branched polymers.

\section{Pillararenes-based MPs}

Pillar[n]arenes (PAs) are 'rising star' macrocyclic hosts in supramolecular host-guest chemistry. The pillar-shaped structure is constructed by the methylene bridges at the para positions of the functionalized aromatic rings. ${ }^{121}$ Compared with other macrocyclic hosts, PAs have unique functionalities with vast advantages that include the following: (i) the capability of selective guest binding owing to its highly rigid and symmetrical structure; (ii) facile functionalization at all the rims or selective rims with one or two substituents employed for the perfection of supramolecular host-guest complexation-mediated superstructures; (iii) good solubility in both organic and aqueous solutions, making PAs a good supplement for other water-soluble macrocyclic hosts with analogous cavity size. ${ }^{122}$ In particular, pillar[5] arene $(\mathrm{P}[5] \mathrm{A})$ and pillar[6]arene $(\mathrm{P}[6] \mathrm{A})$ possess higher electron density than

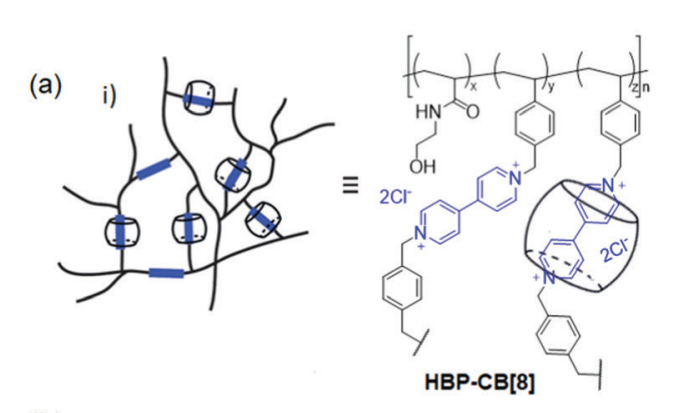

(b)
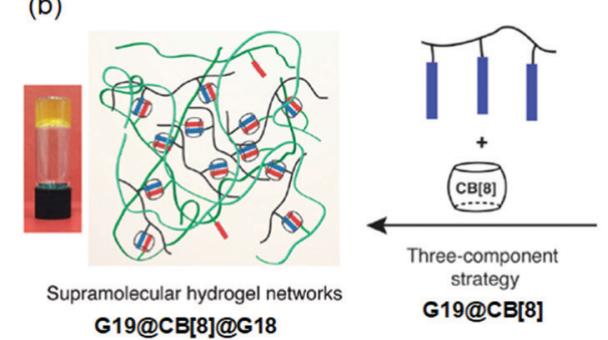

ii)
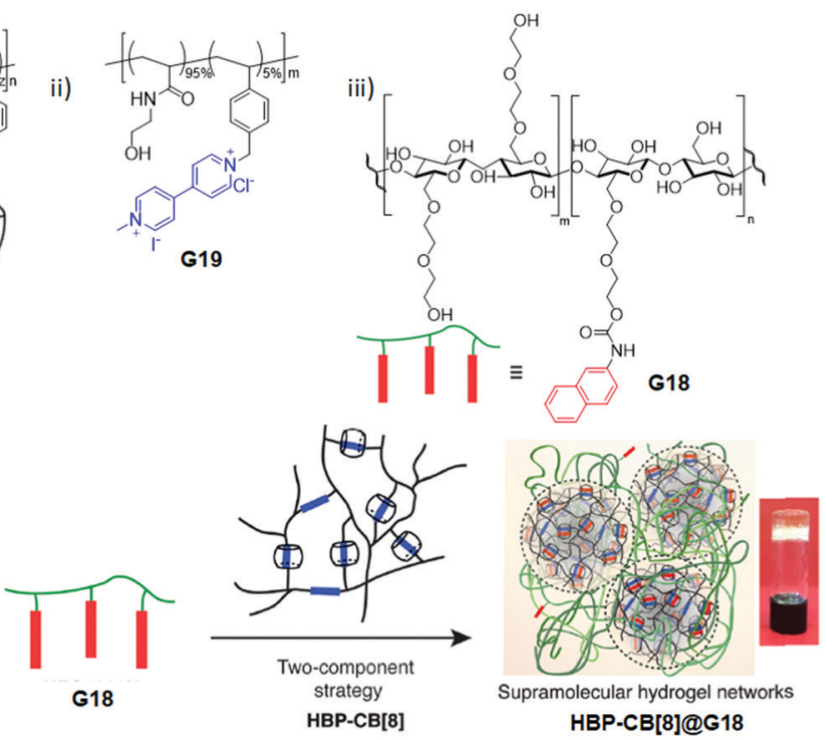

Fig. 14 (a) Structures and representations of the HBP-CB[8], G19, and G18. (b) Hydrogel formation via a two- and three-component strategy from HBP-CB[8] and G19@CB[8]. Reproduced from ref. 120 with permission from John Wiley \& Sons, Inc., Copyright 2017. 
calix-shaped structures, and thus they are accountable for the excellent binding affinity with electron-withdrawing or neutral guests. Therefore, PAs function as potential candidates for the fabrication of diverse supramolecular self-assemblies in the field of rotaxanes, ${ }^{123}$ hybrid materials, ${ }^{124}$ liquid crystals, ${ }^{125}$ hydrogels, ${ }^{126}$ polymers, ${ }^{127-129}$ chemosensors, ${ }^{130,131}$ light-harvesting systems ${ }^{132,133}$ drug deliveries, ${ }^{134}$ and catalysts. ${ }^{135}$

Numerous homologous PAs have been developed via elegant synthetic routes. ${ }^{136}$ Notably, $\mathrm{P}[5] \mathrm{A}$ and $\mathrm{P}[6] \mathrm{A}$ derivatives have been widely employed in the construction of different supramolecular host-guest assemblies due to their facile functionalization and suitable cavity size $(\mathrm{P}[5] \mathrm{A}=4.7 \AA, \mathrm{P}[6] \mathrm{A}=6.7 \AA)$. Owing to the cavity-dependent inclusion in these structures, $\mathrm{P}[6] \mathrm{A}$ can interact with larger-sized guests to form supramolecular complexes in comparison with $\mathrm{P}[5] \mathrm{A}$. The binding affinity of watersoluble PAs with guest molecules is greatly enhanced due to the introduction of cationic or anionic moieties on the PA backbone, leading to the formation of supramolecular amphiphiles. As an example, water-soluble PAs with carboxylate, imidazolium, and trimethylammonium functional groups can offer an appropriate binding environment to different guests via non-covalent/ electrostatic interactions. ${ }^{137}$ Stimuli-responsive MPs have also been constructed by the utilization of stimuli-responsive polymeric hosts and/or guests, affording supramolecular micro- and nanostructures with superior functionalities.

Wang and $\mathrm{Hu}$ et al. ${ }^{138,139}$ developed side-chain polypseudorotaxanes from the $\mathrm{P}[5] \mathrm{A}$-polymeric host and n-octylpyrazinium hexafluorophosphate guest. The disassembly of the polypseudorotaxane system was achieved by adding halide ions, which could be used as an anion-responsive fluorescent sensor. Huang et al. ${ }^{140}$ studied the effects of LCST in a thermoresponsive polymer by PA-based supramolecular host-guest interactions. The LCST behaviour and solubility of the $\mathrm{MV}^{2+}$-based polymer increased when it formed an inclusion complex with suitably-sized $\mathrm{P}[6] \mathrm{A}$ due to the inhibition of interpolymer aggregation. Similarly, Yu et al. ${ }^{141}$ reported the thermoresponsive supramolecular system formed by $\mathrm{P}[10] \mathrm{A}$ and the $\mathrm{MV}^{2+}$-based polymeric guest, and studied their reversible assembly by introducing a competitive guest (1,10-phenanthrolinium).

In 2015, Huang et al. ${ }^{142}$ reported a dual thermo- and photoresponsive supra-amphiphilic polypseudorotaxane, which was constructed by hydrophobic interactions between $\mathrm{P}[7] \mathrm{A}$ and an azobenzene polymer (G20) as shown in Fig. 15. This supraamphiphilic polypseudorotaxane could self-assemble into vesicles $(d=260 \mathrm{~nm})$ with reversible morphological transformations by tuning the solution temperature (LCST) or irradiating with light. Calcein was successfully loaded into these supramolecular vesicles to further investigate the controlled release via irradiation or thermal treatment. For thermal stimulus $\left(60{ }^{\circ} \mathrm{C}\right), 90 \%$ of calcein was released within $10 \mathrm{~h}$ due to the structural disruption into solid NPs. Upon irradiation (365 nm), only $70 \%$ of the calcein was released due to the existence of the cis-trans isomerization equilibrium. They also fabricated DOX-loaded SNPs for self-imaging drug delivery (in vitro/in vivo) with the help of the AIE effect. ${ }^{143}$

Wang et al. ${ }^{144}$ developed a redox responsive supramolecular gel-like network $\left(\mathrm{pFc}^{+}-\mathrm{pP}[6] \mathrm{A}\right)$ through the combination of

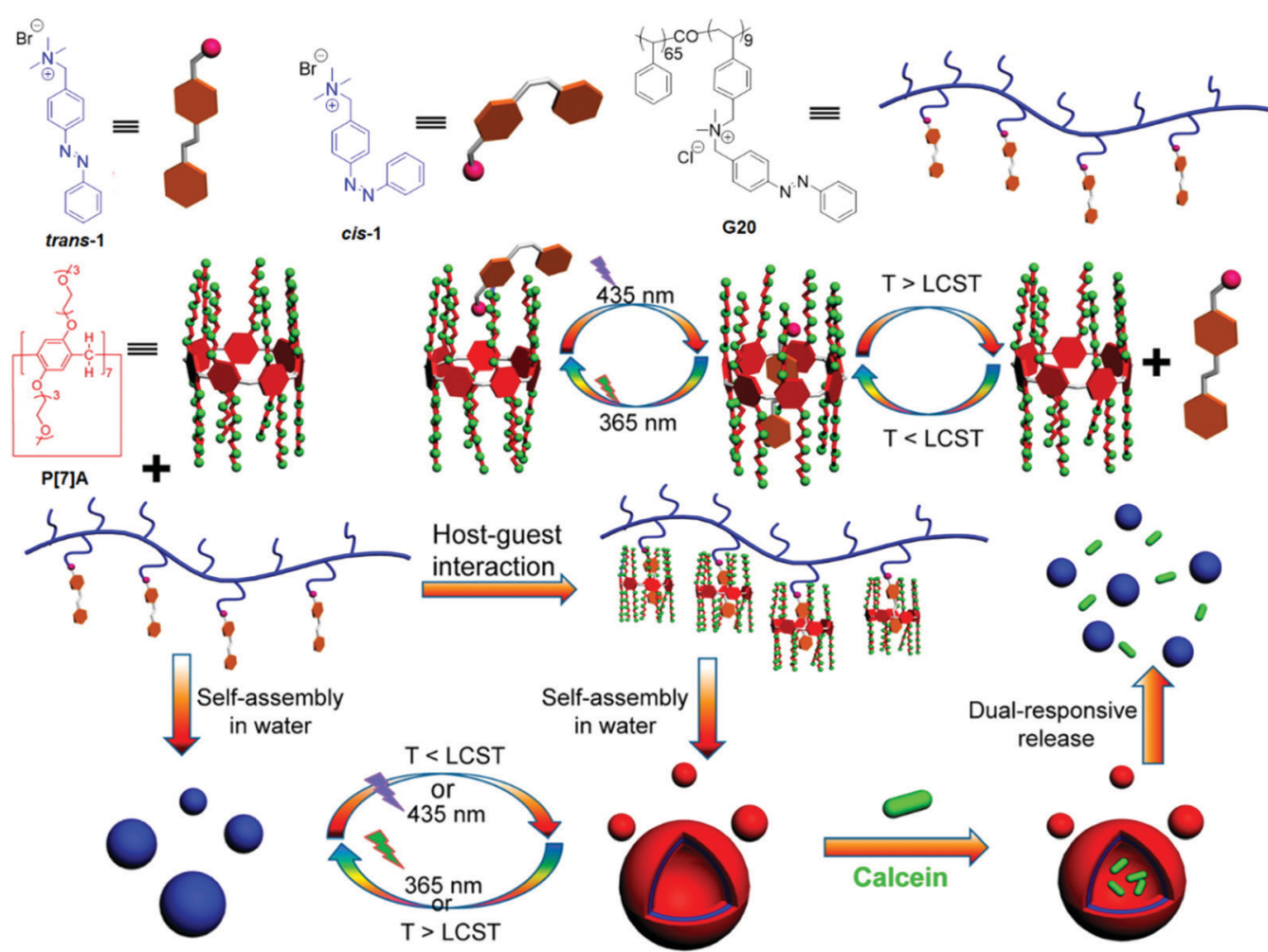

Fig. 15 Chemical structures and representations of P[7]A, azobenzene, G20, and the dual-responsive assembly/disassembly of supramolecular vesicles and calcein release. Reproduced from ref. 142 with permission from the American Chemical Society; Copyright 2015. 
$\mathrm{P}[6] \mathrm{A}$ with ferrocene-functionalized copolymers. Interestingly, the oxidized form of ferrocene $\left(\mathrm{pFc}^{+}\right)$displayed a larger binding affinity with $\mathrm{pP}[6] \mathrm{A}$ than $\mathrm{pFc}$. The redox-responsive assemblies can be controlled by various external stimuli, such as chemical redox reagents and competing hosts. Liao et al. ${ }^{145}$ prepared a multi-responsive supramolecular polymeric gel through hostguest interactions between $\mathrm{pP}[5] \mathrm{A}$ and the bis(pyridinium) dication guest $\left(\mathrm{MV}^{2+}\right)$. The gel to sol transition was achieved by adding a competitive host/guest or by heating. The freeze-dried gel displayed a halo peak at the wide-angle region $\left(2 \theta=25.2^{\circ}\right)$ measured by wide-angle X-ray scattering (WAXS), which may be attributed to the ordered structure of supramolecular complexes and $\pi-\pi$ stacking of $\mathrm{P}[5]$ As. When this hydrogel was heated to $50{ }^{\circ} \mathrm{C}$, the peak intensity decreased, revealing the disassembly of the supramolecular gel networks.

Stimuli-responsive materials play a significant role in the development of smart windows due to the self-adjustment of the window transparency through external environmental stimuli, thus creating a comfortable indoor environment for advanced lifestyles. Inspired by smart materials, Wang and coworkers ${ }^{146}$ synthesized color-switchable thermochromic hydrogel materials based on the host-guest interactions of ethylene glycolfunctionalized $\mathrm{P}[6] \mathrm{A}(\mathrm{EGP}[6] \mathrm{A})$ and the polymeric ferrocene derivative (G21). Due to the efficient EGP[6]A-G21 complexation, the swelling ratio of the EGP[6]A-G21 hydrogel drastically increased to $150 \%$ as compared with the dry G21-gel. The thermo-responsiveness of the EGP[6]A-G21 hydrogel was examined by increasing/decreasing the temperature $\left(40{ }^{\circ} \mathrm{C} / 25{ }^{\circ} \mathrm{C}\right)$, leading to reversible opaque ( $\left.>T_{\text {cloud }}\right) /$ transparency $\left(<T_{\text {cloud }}\right)$ transformation. The reversibility and stability of hydrogels were efficiently maintained for more than 100 cycles without the leakage of EGP[6]A from the hydrogel. On the other hand, the redox responsiveness of the EGP[6]A-G21 hydrogel was achieved by introducing chemical reagents $\left(\left(\mathrm{NH}_{4}\right)_{2} \mathrm{~S}_{2} \mathrm{O}_{8} / \mathrm{N}_{2} \mathrm{H}_{4} \cdot \mathrm{H}_{2} \mathrm{O}\right)$ or through a more favourable electrochemical approach to achieving the warm and cool colour switching (Fig. 16). They have also reported the construction of supramolecular hydrogels with controlled shrinking behaviour ( $89.2 \%$ in wt), which was achieved by noncovalent interactions between water-soluble $\mathrm{P}[5] \mathrm{A}(\mathrm{WP}[5] \mathrm{A})$ and quaternary ammonium-functionalized copolymer. ${ }^{147}$

Biodegradable polymeric assemblies have played a vital role in reducing antimicrobial resistance and prevent their accumulation. In 2019, Gao and coworkers ${ }^{148}$ developed a supramolecular polymeric system (CP[5]A@G22) from the anionic carboxylatopillar[5]arene $(\mathrm{CP}[5] \mathrm{A})$ and quaternary ammonium polymer (G22). This system showed better antibacterial activity in Gram-positive and methicillin-resistant Staphylococcus aureus (S. aureus) (MRSA). In particular, CP[5]A@G22 material was involved in the selective membranolysis of $S$. aureus rather than E. coli (Fig. 17). The bacterial elimination mechanism was further explained by $\zeta$-potential measurements of CP[5]A@G22 with $S$. aureus, which showed an insignificant change $(-38.5$ to $-41.7 \mathrm{mV}$ ); however, in the case of $\mathrm{CP}[5] \mathrm{A} @ \mathbf{G 2 2}$ with E. coli, an obvious $\zeta$-potential shift was observed $(-45.3$ to $-29.6 \mathrm{mV})$. The above result indicated that the anionic PA and a thicker lipopolysaccharide-linked membrane in $E$. coli inhibited the binding of $\mathrm{CP}[5] \mathrm{A} @ \mathbf{G 2 2}$ to the bacterial surface, thus leading to a selective antibacterial potency toward $S$. aureus. This antibacterial material was then utilized for in vivo MRSA-infected wound healing treatment.

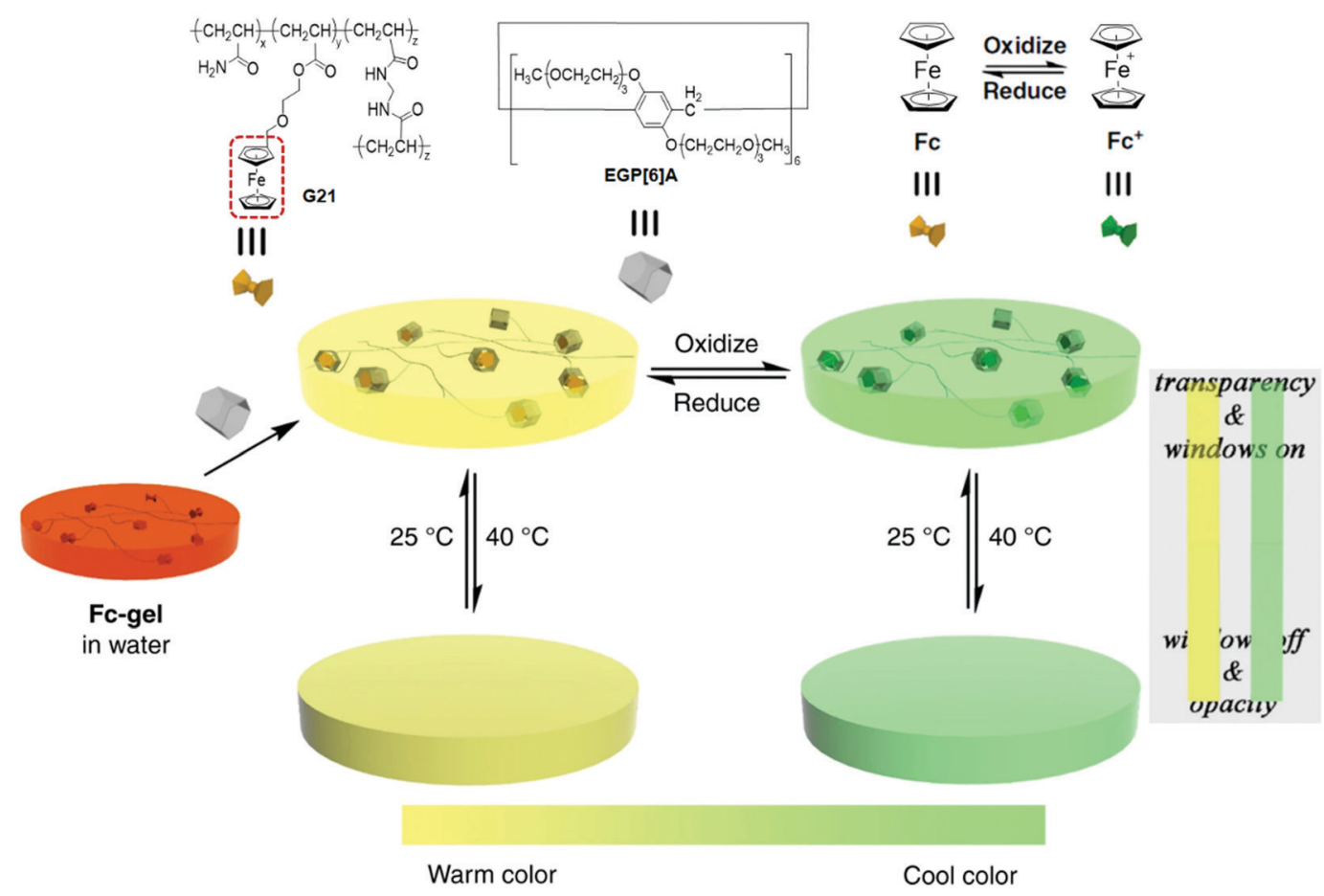

Fig. 16 Chemical structures and schematic representation of G21, Fc, Fc ${ }^{+}$, and EGP[6]A. Warm/cool tone-switchable thermochromic behaviors of the EGP[6]A-G21 hydrogel. Reproduced from ref. 146 with permission from the Nature Publishing Group; Copyright 2018. 

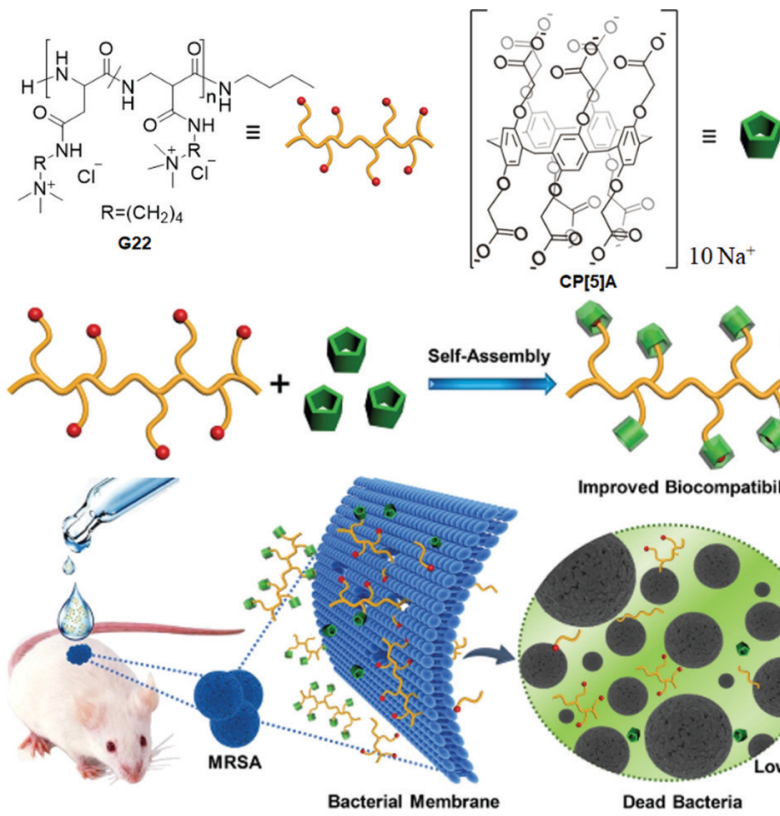

.

Fig. 17 Structures and illustrations of G22 and CP[5]A. Preparation of the supramolecular material (CP[5]A@G22) and its antibacterial activity for MRSA-infected wound healing treatment. Reproduced from ref. 148 with permission from John Wiley \& Sons, Inc., Copyright 2019.

Recently, Xie and Liao et al. prepared a supramolecular polymeric system based on the non-covalent interactions between a pyridinium guest (Py) and a $\mathrm{P}[5] \mathrm{A}$-derived polymeric host (pP[5]A). ${ }^{149}$ The ionic conductivity of the supramolecular complex (pP[5]A@Py) showed greater performance than the complex of $\mathrm{pP}[5] \mathrm{A}$-copolymer@Py. This may be ascribed to the regularity in its structure, which further enhanced the conductivity in the system. Moreover, the glass transition temperature $\left(T_{\mathrm{g}}\right)$ exhibited a progressive decline in the supramolecular polymer in comparison with the individual polymer, indicating that the improved flexibility of the supramolecular polymer could prevent its leakage from the system. Therefore, we conclude that this supramolecular material exhibits good compatibility and efficient tuneable conductivity upon increasing the ratio of the ionic guest.

\section{Summary and outlook}

Over the past decade, significant efforts have been made to achieve efficient and novel functional materials in the field of MPs. These efforts and innovative results indicate the depth and achievement of MPs in spreading their influences in supramolecular and materials chemistry. In the present review, significant properties and potential applications of MPs have been highlighted, which include stimuli-responsive hydrogels, nanocarriers for drug delivery, air-stable metal complexes for CO delivery, adsorbent/adhesive materials for the sensing and removal of toxic cations/anions, and smart windows, etc. Despite the unquestionable success achieved with MPs, there is still of the need for cutting-edge research that is yet to be industrialized using MPs with advanced functionalities and futuristic applications. Hence, this review provides some clues about the construction of supramolecular self-assemblies via macrocycles/small molecules-functionalized polymeric building blocks, tasks for current researchers, and guidelines for future challenges.

MPs with dynamic functionalities can provide a complementary approach to traditional assemblies. In comparison, low molecular weight supramolecular assemblies have lower stability than polymeric assemblies, thus hampering their full realization of realistic applications. Therefore, macrocyclic polymers noncovalently interacting with small molecular guests functionalized by side-chain polymers can provide a route for achieving dynamic MPs with high stability. This noncovalent strategy slows down the molecular exchange via multiple interactions and their polymeric entanglement is responsible for better stability than the analogs of small molecules. Furthermore, the loading of enzymes and other biomaterials into the MPs can be more facilely achieved than covalent chemistry and these materials have great potential applications for long-term drug delivery and therapy.

In the past decades, more MPs have been constructed and utilized for clinical applications, although some significant issues need to be resolved before the clinical application of supramolecular systems, such as stability, sensitivity, specificity, reliability of the platforms, therapeutic efficacy, excretion, and immunological reactions, etc. ${ }^{150,151}$ On the other hand, the fabrication of MPsbased nanosystems with well-defined features, such as size, shape, stability, surface tension, charge, payload and aggregation number are rarely reported and are foremost in the upcoming research. Also, the expansion of nanomedicines with excellent targeting ability and therapeutic efficiency-related investigations are crucial for biomedical remedies.

Undoubtedly, researchers will face many problems that need to be actively addressed; these are related to diverse fields of applications and may be overcome by utilizing the scope of chemistries, new methodologies, and materials available. Moreover, the discovery of new macrocycles with fascinating properties, including inexpensive and facile synthetic routes with reasonable yields, could also be evaluated for replacing available MPs. To predict the properties of newly designed MPs, experimental and theoretical analyses are necessary for the further growth of this field. Moreover, in the case of biomedical applications, MPs disassemble into various parts and try to determine the ultimate destiny of hydrophobic polymeric units.

Progress in the design and construction of fluorescent selfassembled hybrid materials as nanocarriers for therapeutic applications is forthcoming. For example, MPs loaded with new components, including gold nanoparticles (AuNPs), gold nanorods (AuNRs), magnetic NPs, upconversion NPs, and quantum dots, which can produce fluorescent self-assembled hybrid nanomaterials with photodynamic/photothermal properties, stimuli-responsiveness, target sensing, and other bio-related features, will be a success. State-of-the-art studies on MPs, MPsfunctionalized hybrid nanomaterials and their latent practical applications present challenges. These challenges can be fruitfully addressed by the blending of rational materials design and 
inter-disciplinary teamwork with active researchers in the biomedical and technological fields.

Ultimately, by merging the scope of macrocyclic polymers and membrane technology, size- and shape-dependent polymeric membranes containing macrocycles can be produced, which will allow for the separation/removal of various analytes, such as cations, anions, small molecules, and complex mixtures. Considering these advantages, these tunable membranes can be used to capture and remove organic/inorganic pollutants from aqueous/organic solvent mixtures with greater accuracy and reliability than commercially available polymeric membranes. These strategies can produce prospective applications for these MPs-based materials, which fulfil the global challenges faced by our modern society.

\section{Conflicts of interest}

There are no conflicts to declare.

\section{Acknowledgements}

This work was supported by the Natural Science Foundation of Jiangsu Province (BK20180055), the Fundamental Research Funds for the Central Universities (NE2019002), and the China Postdoctoral Science Foundation project (2019M661816).

\section{Notes and references}

1 T. F. A. De Greef, M. M. J. Smulders, M. Wolffs, A. P. H. J. Schenning, R. P. Sijbesma and E. W. Meijer, Chem. Rev., 2009, 109, 5687.

2 D. S. Guo and Y. Liu, Chem. Soc. Rev., 2012, 41, 5907.

3 C. Fouquey, J. M. Lehn and A. M. Levelut, Adv. Mater., 1990, $2,254$.

4 J. M. Lehn, Supramolecular Chemistry: Concepts and Perspectives, Wiley-VCH, Weinheim, Germany, 1995.

5 S. Y. Dong, B. Zheng, F. Wang and F. Huang, Acc. Chem. Res., 2014, 47, 1982.

6 B. Zheng, F. Wang, S. Dong and F. Huang, Chem. Soc. Rev., 2012, 41, 1621.

7 P. Wei, X. Yan and F. Huang, Chem. Soc. Rev., 2015, 44, 815.

8 L. Yang, X. Tan, Z. Wang and X. Zhang, Chem. Rev., 2015, 115, 7196.

9 B. Qin, S. Zhang, Q. Song, Z. Huang, J. F. Xu and X. Zhang, Angew. Chem., Int. Ed., 2017, 56, 7649.

10 H. Chen, Z. Huang, H. Wu, J. F. Xu and X. Zhang, Angew. Chem., Int. Ed., 2017, 56, 16575.

11 X. Ma and H. Tian, Acc. Chem. Res., 2014, 47, 1971.

12 H. Zhang, F. Xin, Y. Li, A. Hao, W. An and T. Sun, Prog. Chem., 2010, 22, 2276.

13 R. Dong and J. Hao, Chem. Rev., 2010, 110, 4978.

14 Y. Wang, H. Xu and X. Zhang, Adv. Mater., 2009, 21, 2849.

15 M. Xue, Y. Yang, X. Chi, X. Yan and F. Huang, Chem. Rev., 2015, 115, 7398.
16 D. Xia, P. Wang, X. F. Ji, N. M. Khashab, J. L. Sessler and F. Huang, Chem. Rev., 2020, 120, 6070.

17 M. J. Monteiro, Macromolecules, 2010, 43, 1159.

18 L. You, D. Zha and E. V. Anslyn, Chem. Rev., 2015, 115, 7840.

19 Y. Han, Z. Meng, Y. X. Ma and C. F. Chen, Acc. Chem. Res., 2014, 47, 2026.

20 A. Harada, Y. Takashima and M. Nakahata, Acc. Chem. Res., 2014, 47, 2028.

21 D. S. Guo and Y. Liu, Acc. Chem. Res., 2014, 47, 1925.

22 N. L. Strutt, H. Zhang, S. T. Schneebeli and J. F. Stoddart, Acc. Chem. Res., 2014, 47, 2631.

23 X. Ma and Y. Zhao, Chem. Rev., 2015, 115, 7794.

24 H. Zhang, G. Grüner and Y. Zhao, J. Mater. Chem. B, 2013, 1, 2542.

25 H. Zhang, R. Zou and Y. Zhao, Coord. Chem. Rev., 2015, 292, 74 .

26 W. Si, P. Xin, Z. T. Li and J. L. Hou, Acc. Chem. Res., 2015, 48, 1612.

27 H. Zhang, X. Ma, J. Guo, K. T. Nguyen, Q. Zhang, X. J. Wang, H. Yan, L. Zhu and Y. Zhao, RSC Adv., 2013, 3, 368.

28 X. Y. Hu, T. Xiao, C. Lin, F. Huang and L. Wang, Acc. Chem. Res., 2014, 47, 2041.

29 I. Nierengarten, R. Deschenaux and J. F. Nierengarten, Chimia, 2016, 70, 61.

30 Y. C. Chang, Y. Jiao, H. E. Symons, J. F. Xu, C. J. Faul and X. Zhang, Chem. Soc. Rev., 2019, 48, 989.

31 G. H. Ouyang and M. H. Liu, Mater. Chem. Front., 2020, 4, 155.

32 L. C. Liu, L. L. Rui, Y. Gao and W. A. Zhang, Polym. Chem., 2014, 5, 5453.

33 V. Balzani, A. Credi, S. Silvi and M. Venturi, Chem. Soc. Rev., 2006, 35, 1135.

34 F. Seidi, A. A. Shamsabadi, M. Amini, M. Shabanian and D. Crespy, Polym. Chem., 2019, 10, 3674.

35 K. G. Liu, X. H. Jiang and P. Hunziker, Nanoscale, 2016, 8, 16091.

36 N. Kaur, P. Kaur and K. Singh, RSC Adv., 2014, 4, 29340.

37 G. S. Ananchenko, I. L. Moudrakovski, A. W. Coleman and J. A. Ripmeester, Angew. Chem., Int. Ed., 2008, 120, 5698.

38 L. H. Qi, J. D. Ding, X. Q. Ma, X. W. Guan, W. Zhu, H. Yao, Y. M. Zhang, T. B. Wei and Q. Lin, Soft Matter, 2019, 15, 6836.

39 W. Shi, L. Zhang, J. Deng, D. Wang, S. Sun, W. Zhao and C. Zhao, J. Membr. Biol., 2015, 480, 139.

40 Y. Zheng, A. Tang, Z. Weng, S. Cai, Y. Jin, Z. Gao and C. Gao, Macromol. Chem. Phys., 2015, 217, 380.

41 D. D. Chang, D. Han, W. H. Yan, Z. Y. Yuan, Q. C. Wang and L. Zou, RSC Adv., 2018, 8, 13722.

42 Y. X. Sun, J. Y. Zhu, W. X. Qiu, Q. Lei, S. Chen and X. Z. Zhang, ACS Appl. Mater. Interfaces, 2017, 9, 42622.

43 H. F. Liu, Y. G. Luan, B. Koo, E. Y. Lee, J. Joo, T. N. T. Dao, F. Zhao and L. L. Zhong, ACS Sustainable Chem. Eng., 2019, 7, 5440 .

44 Z. B. Zhang, K. C. Sun, L. Q. Jin, C. S. Xie and S. J. Li, Org. Chem. Front., 2020, 7, 1453.

45 K. Tungala, P. Adhikary, V. Azmeera, K. Kumar, K. Ramesh and S. Krishnamoorthi, RSC Adv., 2016, 6, 41594. 
46 G. W. Gokel, W. M. Leevy and M. E. Weber, Chem. Rev., 2004, 104, 2723.

47 S. Y. Dong, Y. Luo, X. Z. Yan, B. Zheng, X. Ding, Y. H. Yu, Z. Ma, Q. L. Zhao and F. H. Huang, Angew. Chem., Int. Ed., 2011, 50, 1905.

48 M. M. Zhang, D. H. Xu, X. Z. Yan, J. Z. Chen, S. Y. Dong, B. Zheng and F. H. Huang, Angew. Chem., Int. Ed., 2012, 51, 7117.

49 X. Wang, G. Ye and X. Wang, Sens. Actuators, B, 2014, 193, 413.

50 X. Xiong, Y. Chen, S. Feng and W. Wang, J. Polym. Sci., Part A: Polym. Chem., 2010, 48, 3515.

51 X. W. Liu, S. Zhu, S. R. Wu, P. Wang and G. Z. Han, Colloids Surf., A, 2013, 417, 140.

52 H. Wang, C. N. Zhu, H. Zeng, X. Ji, T. Xie, X. Yan, Z. L. Wu and F. Huang, Adv. Mater., 2019, 31, 1807328.

53 S. Choi, T.-W. Kwon, A. Coskun and J. W. Choi, Science, 2017, 357, 279.

54 M. Nakahata, S. Mori, Y. Takashima, H. Yamaguchi and A. Harada, Chem, 2016, 1, 766.

55 T. Kakuta, Y. Takashima, T. Sano, T. Nakamura, Y. Kobayashi, H. Yamaguchi and A. Harada, Macromolecules, 2015, 48, 732.

56 L. Peng, H. Zhang, A. Feng, M. Huo, Z. Wang, J. Hu, W. Gao and J. Yuan, Polym. Chem., 2015, 6, 3652.

57 G. Li, J. Wu, B. Wang, S. Yan, K. Zhang, J. Ding and J. Yin, Biomacromolecules, 2015, 16, 3508.

58 Y. Takashima, K. Yonekura, K. Koyanagi, K. Iwaso, M. Nakahata, H. Yamaguchi and A. Harada, Macromolecules, 2017, 50, 4144.

59 S. Tamesue, S. Noguchi, Y. Kimura and T. Endo, ACS Appl. Mater. Interfaces, 2018, 10, 27381.

60 Z. Deng, Y. Guo, X. Zhao, P. X. Ma and B. Guo, Chem. Mater., 2018, 30, 1729.

61 N. Rajendiran, G. Venkatesh and J. Saravanan, Spectrochim. Acta, Part A, 2014, 129, 157.

62 S. Terabe, Y. Miyashita, O. Shibata, E. R. Barnhart, L. R. Alexander, D. G. Patterson, B. L. Karger, K. Hosoya and N. Tanaka, J. Chromatogr. A, 1990, 516, 23.

63 G. C. Yu, K. C. Jie and F. H. Huang, Chem. Rev., 2015, 115, 7240 .

64 A. Harada, R. Kobayashi, Y. Takashima, A. Hashidzume and H. Yamaguchi, Nat. Chem., 2010, 3, 34.

65 A. Bertrand, M. Stenzel, E. Fleury and J. Bernard, Polym. Chem., 2012, 3, 377.

66 N. Cakir, G. Hizal and C. R. Becer, Polym. Chem., 2015, 6, 6623.

67 L. Zhang, G. R. Qiu, F. F. Liu, X. Liu, S. D. Mu, Y. R. Long, Q. X. Zhao, Y. Liu and H. B. Gu, React. Funct. Polym., 2018, 132, 60 .

68 H. Noh, S. Myung, M. J. Kim and S. K. Yang, Polymer, 2019, $175,65$.

69 S. Tamesue, Y. Takashima, H. Yamaguchi, S. Shinkai and A. Harada, Angew. Chem., Int. Ed., 2010, 49, 7461.

70 S. H. Wang, Q. X. Shen, M. H. Nawaz and W. A. Zhang, Polym. Chem., 2013, 4, 2151.

71 D. S. Wang, M. Wagner, H. J. Butt and S. Wu, Soft Matter, 2015, 11, 7656.
72 H. Yao, Y. Ning, C. P. Jesson, J. He, R. Deng, W. Tian and S. P. Armes, ACS Macro Lett., 2017, 6, 1379.

73 M. Nakahata, Y. Takashima, H. Yamaguchi and A. Harada, Nat. Commun., 2011, 2, 511.

74 F. Szillat, B. V. K. J. Schmidt, A. Hubert, C. Barner-Kowollik and H. Ritter, Macromol. Rapid Commun., 2014, 35, 1293.

75 M. Hetzer, C. Fleischmann, B. V. K. J. Schmidt, C. BarnerKowollik and H. Ritter, Polymer, 2013, 54, 5141.

76 R. Namgung, Y. M. Lee, J. Kim, Y. Jang, B. H. Lee, I. S. Kim, P. Sokkar, Y. M. Rhee, A. S. Hoffmann and W. J. Kim, Nat. Commun., 2014, 5, 3702.

77 Y. G. Jia and X. X. Zhu, Langmuir, 2014, 30, 11770.

78 Y. G. Jia and X. X. Zhu, Chem. Mater., 2015, 27, 387.

79 N. Zhou, L. Peng, S. Salgado, J. Y. Yuan and X. S. Wang, Angew. Chem., Int. Ed., 2017, 56, 6246.

80 B. C. Hamann, K. D. Shimizu and J. R. Jr, Angew. Chem., Int. Ed. Engl., 1996, 35, 1326.

81 H. Chen, S. Jia, F. Qi, F. Zou, Y. Hou, K. Koh and Y. Yin, Sens. Actuators, B, 2016, 225, 504.

82 R. K. Castellano and J. Rebek, J. Am. Chem. Soc., 1998, $120,3657$.

83 D. S. Guo, K. Wang and Y. Liu, J. Incl. Phenom. Macrocycl. Chem., 2008, 62, 1.

84 T. Haino, E. Hirai, Y. Fujiwara and K. Kashihara, Angew. Chem., Int. Ed., 2010, 49, 7899.

85 A. R. Hajipour, S. Habibi and A. E. Ruoho, J. Appl. Polym. Sci., 2010, 118, 818.

86 A. Hajipour, S. Habibi and A. E. Ruoho, Chin. J. Polym. Sci., 2010, 28, 731.

87 B. B. Adhikari, M. Kanemitsu, H. Kawakita, Jumina and K. Ohto, Chem. Eng. J., 2011, 172, 341.

88 S. Wiktorowicz, H. Tenhu and V. Aseyev, Polym. Chem., 2013, 4, 2898.

89 S. Wiktorowicz, H. Tenhu and V. Aseyev, Macromolecules, 2013, 46, 6209.

90 U. Balami and D. K. Taylor, React. Funct. Polym., 2014, 81, 54.

91 E. S. Silver, B. M. Rambo, C. W. Bielawski and J. L. Sessler, J. Am. Chem. Soc., 2014, 136, 2252.

92 X. F. Ji, C. X. Guo, W. Chen, L. L. Long, G. W. Zhang, N. M. Khashab and J. L. Sessler, Chem. - Eur. J., 2018, 24, 15791.

93 X. F. Ji, H. Wang, Y. Li, D. Y. Xia, H. Li, G. P. Tang, J. L. Sessler and F. H. Huang, Chem. Sci., 2016, 7, 6006.

94 X. F. Ji, X. D. Chi, M. Ahmed, L. L. Long and J. L. Sessler, Acc. Chem. Res., 2019, 52, 1915.

95 X. F. Ji, M. Ahmed, L. L. Long, N. M. Khashab, F. H. Huang and J. L. Sessler, Chem. Soc. Rev., 2019, 48, 2682.

96 R. Brhrend, E. Meyer and F. Rusche, Liebigs Ann. Chem., 1905, 339, 1.

97 W. A. Freeman, W. L. Mork and N. Y. Shih, J. Am. Chem. Soc., 1981, 103, 7367.

98 J. Kim, I. S. Jung, S. Y. Kim, E. Lee, J. K. Kang, S. Sakamoto and K. Yamaguchi, J. Am. Chem. Soc., 2000, 122, 540.

99 K. Jansen, H. J. Buschmann, A. Wego, D. Döpp, C. Mayer, H. J. Drexler, H. J. Holdt and E. J. Schollmeyer, J. Inclusion Phenom. Mol. Recognit. Chem., 2001, 39, 357. 
100 A. Day, A. P. Amold, R. J. Blanch and B. J. Snushall, Org. Chem., 2001, 66, 8094.

101 M. Spulber, S. Schlick and F. A. Villamena, J. Phys. Chem. A, 2012, 116, 8475.

102 H. J. Buschmann, E. Cleve and E. Schollmeyer, Inorg. Chim. Acta, 1992, 193, 93.

103 H. J. Buschmann, K. Jansen, C. Meschke and E. Schollmeyer, J. Solution Chem., 1998, 27, 135.

104 H. Chen, S. Hou, H. Ma, X. Li and Y. Tan, Sci. Rep., 2016, 6, 20722.

105 E. R. Janecek, J. R. McKee, C. S. Tan, A. Nykanen, M. Kettunen, J. Laine, O. Ikkala and O. A. Scherman, Angew. Chem., Int. Ed., 2015, 54, 5383.

106 J. Liu, C. S. Y. Tan and O. A. Scherman, Angew. Chem., Int. Ed., 2018, 57, 8854.

107 W. L. Mock and N. Y. Shih, J. Org. Chem., 1983, 48, 3617. 108 W. L. Mock and N. Y. Shih, J. Org. Chem., 1986, 51, 4440. 109 W. L. Mock and N. Y. Shih, J. Org. Chem., 1988, 110, 4706.

110 E. A. Appel, F. Biedermann, U. Rauwald, S. T. Jones, J. M. Zayed and O. A. Scherman, J. Am. Chem. Soc., 2010, 132, 14251.

111 J. Zhang, R. J. Coulston, S. T. Jones, J. Geng, O. A. Scherman and C. Abell, Science, 2012, 335, 690.

112 J. R. McKee, E. A. Appel, J. Seitsonen, E. Kontturi, O. A. Scherman and O. Ikkala, Adv. Funct. Mater., 2014, 24, 2706.

113 X. Xu, E. A. Appel, X. Liu, R. M. Parker, O. A. Scherman and C. Abell, Biomacromolecules, 2015, 16, 2743.

114 J. Cao, L. W. Meng, S. Zheng, Z. H. Li, J. Jiang and X. Y. Lv, Int. J. Polym. Mater. Polym. Biomater., 2016, 65, 537.

115 M. M. Zhang, X. Z. Yan, F. H. Huang, Z. B. Niu and H. W. Gibson, Acc. Chem. Res., 2014, 47, 1995.

116 T. X. Zhang, Z. Z. Zhang, Y. X. Yue, X. Y. Hu, F. Huang, L. Shi, Y. Liu and D. S. Guo, Adv. Mater., 2020, 32, 1908435.

117 J. D. Barrio, P. N. Horton, D. Lairez, G. O. Lloyd, C. Toprakcioglu and O. A. Scherman, J. Am. Chem. Soc., 2013, 135, 11760.

118 E. Elacqua, X. L. Zheng and M. Weck, ACS Macro Lett., 2017, 6, 1060.

119 D. Wu, Y. Li, J. Yang, J. Shen, J. Zhou, Q. L. Hu, G. C. Yu, G. P. Tang and X. Y. Chen, ACS Appl. Mater. Interfaces, 2017, 9, 44392.

120 C. S. Y. Tan, J. Liu, A. S. Groombridge, S. J. Barrow, C. A. Dreiss and O. A. Scherman, Adv. Funct. Mater., 2018, 28, 1702994.

121 H. Zhang, Z. Liu and Y. Zhao, Chem. Soc. Rev., 2018, 47, 5491.

122 D. Cao, Y. Kou, J. Liang, Z. Chen, L. Wang and H. Meier, Angew. Chem., Int. Ed., 2009, 48, 9721.

123 X. B. Hu, L. Chen, W. Si, Y. Yu and J. L. Hou, Chem. Commun., 2011, 47, 4694.

124 Z. B. Zhang, Q. Zhao, J. Y. Yuan, M. Antonietti and F. H. Huang, Chem. Commun., 2014, 50, 2595.

125 I. Nierengarten, S. Guerra, M. Holler, J. F. Nierengarten and R. Deschenaux, Chem. Commun., 2012, 48, 8072.
126 J. Huaqiang, Z. Fengbo, X. Hao, W. Z. Liang and F. H. Huang, Macromol. Rapid Commun., 2017, 38, 1700232.

127 F. Q. Ye, R. J. Wei, L. Y. Wang, H. Meier and D. R. Cao, RSC Adv., 2016, 6, 89810.

128 Z. Li, X. Li and Y. W. Yang, Small, 2019, 1805509.

129 X. Li, Z. Li and Y. W. Yang, Adv. Mater., 2018, 30, 1800177.

130 Y. Y. Chen, G. F. Gong, Y. M. Zhang, Y. Q. Fan and Q. Lin, Dyes Pigm., 2019, 171, 107706.

131 L. Shao, J. Sun, B. Hua and F. Huang, Chem. Commun., 2018, 54, 4866.

132 L. Xu, Z. Wang, R. Wang, L. Wang, X. He, H. Jiang, H. Tang, D. Cao and B. Z. Tang, Angew. Chem., Int. Ed., 2019, 58, 1.

133 X. H. Wang, N. Song, W. Hou, C. Y. Wang, Y. Wang, J. Tang and Y. W. Yang, Adv. Mater., 2019, 31, e1903962.

134 X. Huang, S. S. Wu, X. K. Ke, X. Y. Li and X. Z. Du, ACS Appl. Mater. Interfaces, 2017, 9, 19638.

135 K. Wang, J. H. Jordan, K. Velmurugan, X. Tian, M. Zuo, X.-Y. Hu and L. Wang, Angew. Chem., Int. Ed., 2020, DOI: 10.1002/anie.202010150.

136 T. Ogoshi and T. A. Yamagishi, Eur. J. Org. Chem., 2013, 2961.

137 L. Shangguan, B. Shi, Q. Chen, Y. Li, H. Zhu, Y. Liu, H. Yao and F. Huang, Tetrahedron Lett., 2019, 150949.

138 S. Sun, X. Y. Hu, D. Z. Chen, J. B. Shi, Y. P. Dong, C. Lin, Y. Pan and L. Y. Wang, Polym. Chem., 2013, 4, 2224.

139 S. Sun, J. B. Shi, Y. P. Dong, C. Lin, X. Y. Hu and L. Y. Wang, Chin. Chem. Lett., 2013, 24, 987.

140 X. F. Ji, J. Z. Chen, X. D. Chi and F. H. Huang, ACS Macro Lett., 2014, 3, 110.

141 G. C. Yu, J. Zhou and X. D. Chi, Macromol. Rapid Commun., 2015, 36, 23.

142 X. D. Chi, X. F. Ji, D. Y. Xia and F. H. Huang, J. Am. Chem. Soc., 2015, 137, 1440.

143 G. C. Yu, R. Zhao, D. Wu, F. W. Zhang, L. Shao, J. Zhou, J. Yang, G. P. Tang, X. Y. Chen and F. H. Huang, Polym. Chem., 2016, 7, 6178.

144 W. Xia, M. F. Ni, C. H. Yao, X. L. Wang, D. Z. Chen, C. Lin, X. Y. Hu and L. Y. Wang, Macromolecules, 2015, 48, 4403.

145 J. X. Chang, Q. H. Zhao, L. Kang, H. M. Li, M. R. Xie and X. J. Liao, Macromolecules, 2016, 49, 2814.

146 S. Wang, Z. Q. Xu, T. T. Wang, T. X. Xiao, X. Y. Hu, Y. Z. Shen and L. Y. Wang, Nat. Commun., 2018, 9, 1737.

147 S. Wang, Z. Xu, T. T. Wang, X. Liu, Y. M. Lin, Y. Z. Shen, C. Lin and L. Y. Wang, J. Photochem. Photobiol., A, 2018, 355,60 .

148 S. Z. Yan, S. Chen, X. B. Gou, J. Yang, J. X. An, X. Y. Jin, Y. W. Yang, L. Chen and H. Gao, Adv. Funct. Mater., 2019, 29, 1904683.

149 Y. Wu, H. F. Li, Y. Q. Yan, X. T. Shan, M. Zhao, Q. H. Zhao, X. J. Liao and M. R. Xie, ACS Macro Lett., 2019, 8, 1588.

150 J. Tian, B. Huang, M. H. Nawaz and W. Zhang, Coord. Chem. Rev., 2020, 420, 213410.

151 H.-B. Cheng, Y. Li, B. Z. Tang and J. Yoon, Chem. Soc. Rev., 2020, 49, 21. 